\title{
Net benefits of smallholder dairy cattle farms in Senegal can be significantly increased through the use of better dairy cattle breeds and improved management practices
}

\author{
K. Marshall, ${ }^{1 *}$ ๑ G. R. Salmon, ${ }^{2} \odot$ S. Tebug, ${ }^{1}$ J. Juga, ${ }^{3} \odot$ M. MacLeod, ${ }^{2} \odot$ J. Poole, ${ }^{1} \odot$ I. Baltenweck, ${ }^{1}$ \\ and A. Missohou ${ }^{4}$ \\ ${ }^{1}$ International Livestock Research Institute, PO Box 30709, Nairobi 00100, Kenya \\ ${ }^{2}$ Land Economy, Environment \& Society, Scotland's Rural College (SRUC), Peter Wilson Building, Kings Buildings, West Mains Road, \\ Edinburgh EH9 3JG, United Kingdom \\ ${ }^{3}$ Department of Agricultural Sciences, Animal Science Research, Koetilantie 5, 00014, University of Helsinki, Finland \\ ${ }^{4}$ Ecole Inter-Etats des Sciences et Médecine Vétérinaires (EISMV), Dakar, Senegal BP 5077
}

\section{ABSTRACT}

Senegal, located in West Africa, is an example of a low- to middle-income country where the government has prioritized improving livestock production self-sufficiency, with a strong focus on dairy. Among other initiatives, the use of exotic dairy cattle has been promoted, despite no evidence for the potential livelihood benefits (or otherwise) to smallholder farmers on adopting the new genetics. The current work fills this evidence gap by performing a farm-level economic study comparing the keeping of different breed and cross-breed types of dairy cattle under different management levels. Data for the study were obtained by monitoring 220 smallholder dairy cattle farms, with a combined cattle population of about 3,000 animals, over an almost 2-yr period. Findings of the study suggest that the most net-beneficial and cost-beneficial dairy cattle enterprise that could be used by the smallholder farmers was to keep crossbred indigenous zebu by exotic Bos taurus animals under management standards that are considered good compared with local standards. This dairy enterprise type was 7.4-fold more net beneficial and had a 1.4-fold more favorable cost-benefit ratio than the traditional system of keeping indigenous zebu animals under poor (low-input) management. Interestingly, the keeping of (near) pure B. taurus dairy cattle resulted in the highest milk yields and thus benefit from milk, but was not the most net beneficial due to the high costs of keeping these animals, particularly in terms of feed. We also found that increasing the management

Received July 26, 2019.

Accepted April 10, 2020.

*Corresponding author: kmarshall@cgiar.org level of any of the breed or cross-breed types under consideration, including the indigenous zebu animals, resulted in an increased net benefit of 2.2- to 2.9-fold. Results of this economic analysis are discussed as part of a broader trade-off analysis, resulting in recommendations to strengthen the Senegal dairy sector. The combined intervention of improved dairy cattle genetics and management is considered a promising intervention to improve livelihoods of the rural poor as well as livestock production self-sufficiency for Senegal; some other system constraints are addressed.

Key words: smallholder, dairy cattle, Senegal, breed comparison, net benefit

\section{INTRODUCTION}

In low- to middle-income countries (LMIC), the demand for animal-source foods is predicted to continue to grow for several decades, particularly in countries of sub-Saharan Africa (Alexandratos and Bruinsma, 2012; Baldi and Gottardo, 2017). This growth is largely driven by increasingly diverse diets among growing higher-earning, urban populations (Delgado et al., 2001; Herrero et al., 2009). Currently, much of this demand is met by "low-input low-output," risk averse, smallholder or pastoral livestock keepers (FAO, 2012; Andrieu et al., 2015). Looking toward the future, these systemstransformed into more profitable and sustainable enterprises - are considered viable and important options to help meet the rising demand for animal-source food (ILRI, 2019).

Senegal is an example of an LMIC where the government has prioritized improving livestock production self-sufficiency, with a strong focus on dairy. Currently, Senegal imports large amounts of dairy products, as domestic production is unable to meet demand (Seck et al., 2016). Local milk is mainly produced by cattle 
kept in smallholder or pastoral systems (Seck et al., 2016). Milk yields are low, attributed to the low genetic potential of the indigenous cattle breeds for milk, the harsh environmental conditions under which the animals must perform, and the general lack of key inputs, including feed and veterinary services. As part of larger initiatives to increase domestic dairy production, the Senegalese government has promoted the use of exotic dairy cattle through subsidized AI campaigns (operating from 1994 to at least 2012), and currently has an emphasis on "high-genetic-potential livestock" in its National Program for Livestock Development (Diouf et al., 2016; Seck et al., 2016). Despite these efforts, no evidence base on potential livelihood benefits (or otherwise) was available for farmers to make informed decisions on whether to engage in the new dairy cattle genetics. This is important because although food security is a global challenge and national governments have their own agendas to improve domestic food production, it will be up to local stakeholders and individual livestock keepers to apply interventions at the farm level which will shape system transformation and increased production.

This paper contributes to this far-level consideration of the "most appropriate" actions to take for future livestock production, specifically considering the choice of dairy cattle enterprise type (defined as breed type of cattle kept and level of inputs they receive) in household dairy systems in Senegal. A net benefit analysis is presented for several different dairy enterprise types, from indigenous breeds kept under traditional management to improved breeds (crossbreds and exotics) kept under improved management, that are currently being practiced. The economic analysis presented here feeds into a broader trade-off analysis, resulting in recommendations to strengthen the Senegal dairy sector.

\section{MATERIALS AND METHODS}

\section{Background to Study}

This work is part of the "Senegal Dairy Genetics Project" (https://senegaldairy.wordpress.com/) which had a key objective of identifying the most appropriate dairy breed or cross-breed type and management level combination, for low- to medium-input household dairy enterprises in selected production systems in Senegal. The project was primarily funded by the Finnish Ministry of Foreign Affairs, through the FoodAfrica program, and the CGIAR Research Program on Livestock and Fish (International Livestock Research Institute, Nairobi, Kenya).

\section{Study Site Description}

Senegal, located in West Africa, has a tropical climate with 2 seasons: dry from November to May and rains from June to October (Seck et al., 2016). There are 7 distinct agro-ecological zones; of these, the Groundnut Basin (Bassin arachidier), with a comparatively favorable climate, has Senegal's highest densities of human and livestock populations and crop production (Beal et al., 2015). Subsequently, this region's cattle systems have experienced varying levels of intensification, with examples of introduced "exotic" breed types (largely through the state AI programs) and some improved feeding regimens (Broutin and Diokhané, 2000; Seck et al., 2016). Due to the presence of cattle of different breed and cross-breed types, the regions of Thiès and Diourbel (both in the Groundnut Basin) were chosen as study sites for the Senegal Dairy Genetics project (Tebug et al., 2018). Thiès has an average annual rainfall of $503 \mathrm{~mm}$ and an average temperature of $25.7^{\circ} \mathrm{C}$ (ranging from an average in January of $23.3^{\circ} \mathrm{C}$, to an average in June of $27.6^{\circ} \mathrm{C}$ ). Diourbel has an average annual rainfall of $539 \mathrm{~mm}$ and an average temperature of $27.9^{\circ} \mathrm{C}$ (ranging from an average in January of $24.3^{\circ} \mathrm{C}$, to an average in June of $30.5^{\circ} \mathrm{C}$; Climate-Data.org, 2019). Cattle in these regions are largely reared in lowto medium-input agro-pastoral systems, relying highly on natural pastures and crop residues, with additional supplementation with feed concentrates (Tebug et al., 2018; Salmon, 2017). See Appendix for further feed ration information.

\section{Household Selection}

Households were purposely selected for inclusion in the study as follows. A list of dairy cattle-keeping households (618) were identified within the sites based on information provided by key informants (such as service providers, staff of the Senegalese Ministry of Livestock, as well as dairy cattle keepers themselves). These were surveyed for basic information about their household dairy enterprise, including number of cattle kept and their breed type. From this, 246 households were selected to participate in the study, based on willingness to participate and maximization of diversity of the cattle breeds represented. Of these, 220 (111 from the Thiès region and 109 from the Diourbel region) were included in the final analysis, the others being excluded for various reasons, such as not completing all survey rounds. Throughout this process, a dairy cattle-keeping household was defined as a household keeping one or more cattle for the purpose of producing 
milk for human consumption, regardless of whether the milk was consumed by household members or sold and consumed by others.

\section{Surveys and Data Collection}

Data collection from project households and animals was performed via 14 rounds of surveys, between May 2013 and April 2015. The surveys were implemented in the local language of Wolof by a team of trained enumerators. The survey respondents included the household head (most commonly male, but female in $7.5 \%$ of households), other household members (both male and female), and hired herders (male), as appropriate to particular survey questions.

The first survey round (May to July 2013) was a baseline survey, collecting general information on the households (such household membership, livelihood activities, and asset base) as well as information relevant to the household dairy enterprise. The second survey round (July to September 2013) represented initiation of the longitudinal monitoring period, which extended for 22 mo. During the second survey round, a complete animal census was taken and animals ear-tagged such that they could be individually monitored (except for male animals from the indigenous zebu breed, for which data were collected group-wise for different groups of animals). For each of survey rounds 3 to 14, implemented at approximately equal time intervals between September 2013 and April 2015, information was obtained for the period between that survey visit and the previous one, based on a combination of farmer recall and farmer recording. This included animal performance (e.g., milk yield and reproductive performance), animal management (e.g., healthcare, feeding and herding practices), and economics of the dairy enterprise (including benefits such as income from the sale of milk or animals, and costs such as labor, animal healthcare, animal feed, and marketing). All survey materials and associated training manuals are available at http:// data.ilri.org/portal/.

Following each survey round, the collected data were entered into a CSPro database (https://www.census .gov/data/software/cspro.html) by the enumerators. Basic checks on the data were performed (with any resultant data queries checked with the enumerator or survey respondent). The data were then collated across enumerators and survey rounds in a MySQL database.

Approval to undertake this work in Senegal was granted by the Direction de la Planification, de la Recherche et des Statistiques, Division de la Recherche, based on the recommendation of the Comité National d'Ethique pour la Recherche en Santé (permit
409/MSAS/DPRS/DR), Ministère de la Santé et de l'Action Sociale, Fann Résidence, Rue Aimé Césaire, Dakar-Sénégal. Approvals were also obtained from the Institutional Research Ethics Committee (IREC; reference number IREC2013-02) and Animal Care and Use Committee (IACUC; reference number IACUC2013-06) of the International Livestock Research Institute (ILRI; Nairobi, Kenya). The ILRI IREC is registered by the National Commission for Science, Technology and Innovation (NACOSTI) in Kenya (registration number NACOSTI/NBC/AC/01813) and is accredited to grant ethical approval to research projects involving human subjects: this approval is therefore recognized by the government of Kenya (where ILRI is headquartered). The IACUC is a self-regulating entity that was established by ILRI for purposes of overseeing and evaluating all aspects of ILRI's animal care and use program.

\section{Cattle Breed Groups}

All cattle in the study were assigned to a breed group, which represented the main breed or cross-breed types of cattle present. These were indigenous zebu (IZ); indigenous zebu crossbred with Guzerat $(\mathbf{I Z} \times \mathbf{G Z})$; indigenous zebu crossbred with recently introduced exotic $B$. taurus $(\mathbf{I Z} \times \mathbf{B T})$; indigenous zebu crossed with a higher proportion of $B$. taurus or any pure B. taurus animals (BT), and other (subsequently excluded from the analysis). The predominant indigenous zebu breeds were Zebu Gobra and Zebu Maure. The Guzerat is generally considered a tropical dairy or dual-purpose breed of zebu type developed in Brazil from Indian cattle (Peixoto et al., 2010). The main exotic B. taurus breeds were Montbéliarde and Holstein Friesian, both strongly bred for high milk yield.

Animals were assigned to a breed group, based on either genomic information or using ancestry information from farmer recall, as follows. For the genomic assignment, 624 female animals (selected based on having the most informative lactation records) were genotyped using the Bovine 50K SNP chip (Illumina Inc., San Diego, CA). Admixture analysis was performed on this and reference data, using Bayesian Analysis of Population Structure software (version 6; Corander et al., 2008) with predefined clustering. Based on the admixture result, the proportions of ancient (indigenous) zebu (AZ), recent zebu (RZ), ancient taurine (AT), and recent taurine (RT) were derived for each animal. Animals were subsequently assigned to a breed group as given in Table 1. For assignment based on farmer recall, the farmers were asked to name the breeds of each of their animal's grandparents (i.e., sire of sire, dam of sire, sire of dam, and dam of dam). Based on this information, 
Table 1. Criteria for assignment of animals to breed groups, using either genomic information or ancestry information provided by farmer recall

\begin{tabular}{|c|c|c|}
\hline \multirow[b]{2}{*}{ Breed group } & \multicolumn{2}{|c|}{ Based on proportions ${ }^{1}$} \\
\hline & Genotyped & Recall \\
\hline Indigenous zebu (IZ) & $0.88-0.99 \mathrm{AZ}$ & $1.00 \mathrm{AZ}$ \\
\hline \multirow[t]{2}{*}{ IZ crossbred with Guzerat } & $0.39-0.86 \mathrm{AZ}$ & $0.50-0.75 \mathrm{AZ}$ \\
\hline & $0.13-0.61 \mathrm{RZ}$ & $0.25-0.50 \mathrm{RZ}$ \\
\hline \multirow[t]{2}{*}{ IZ crossbred with Bos taurus } & $0.38-0.84 \mathrm{AZ}$ & $0.50-0.75 \mathrm{AZ}$ \\
\hline & $0.13-0.61 \mathrm{RT}$ & $0.25-0.50 \mathrm{RT}$ \\
\hline \multirow{2}{*}{$\begin{array}{l}\text { IZ crossbred with a higher proportion of } \\
B \text {. taurus or pure-bred } B \text {. taurus }\end{array}$} & $0.00-0.36 \mathrm{AZ}$ & $0.00-0.25 \mathrm{AZ}$ \\
\hline & $0.63-0.98 \mathrm{RT}$ & $0.75-1.00 \mathrm{RT}$ \\
\hline
\end{tabular}

${ }^{1}$ Where AZ refers to ancient (indigenous) zebu; RZ refers to recently introduced zebu; and RT refers to recently introduced B. taurus. AZ breeds are mainly Zebu Gobra and Zebu Maure; RZ breeds are mainly Guzerat; and RT breeds are mainly Holstein Friesian and Montbéliarde.

the proportions of AZ, RZ, AT, and RT were derived, and animals similarly assigned to breed groups as per Table 1.

\section{Household Management Levels and Dairy Enterprise Types}

All households were classified into 2 management levels using milk yield as a proxy. Test-day milk yields (excluding milk suckled by calves), expressed in standard deviation units from the breed group mean, were averaged across all animals in a household. Households were ranked based on this average, and the top $50 \%$ of households classified as "better management" and the bottom $50 \%$ as "poorer management." Note that this meant that poorer or better management for one breed group was not necessarily the same level of management as poorer or better for another breed group. For example, when considering annual cost of purchased feed (the main input cost to dairy production, see Results and Discussion), households with poorer management that kept IZ animals had a considerably lower cost than households with poorer management that kept IZ $\times$ BT animals. Thus, to use more informative labeling for the different dairy enterprise types, defined in this work as a combination of breed type and management level, we coded management as,,++++++ , and ++++ , each representing a higher feed cost. For example, the dairy enterprise type with IZ animals and the lowest feed cost was denoted IZ+, whereas the dairy enterprise type with BT animals and the highest feed cost was denoted $\mathrm{BT}++++$. See Table 2 for further details: it is recognized that feed cost is a proxy for management level. Note that only 3 households kept BT animals under poor management, and thus these were excluded from further analysis.

\section{Data Overview}

Throughout this paper, the following terminology is used in relation to animal age classes: calves are $<12$ mo of age; young animals are $\geq 12$ but $<36$ mo of age; and mature (or adult) animals are $\geq 36$ mo of age. Mature females are also referred to as cows.

At the time of census, the number of cattle owned by the 220 study households was 3,202. Household herd size, for all animals including young and calves, ranged from 1 to 74, with the majority (79\%) of households

Table 2. Dairy enterprise types

\begin{tabular}{llll}
\hline Breed group & $\begin{array}{l}\text { Household } \\
\text { management level }\end{array}$ & Feed cost, ${ }^{1} \$$ & Dairy enterprise type $^{2}$ \\
\hline Indigenous zebu (IZ) & Poorer & 132 & $\mathrm{IZ}+$ \\
IZ crossbred with Guzerat & Poorer & 184 & $\mathrm{IZ} \times \mathrm{GZ}+$ \\
IZ & Better & 365 & $\mathrm{IZ}++$ \\
IZ crossbred with Guzerat & Better & 371 & $\mathrm{IZ} \times \mathrm{GZ}++$ \\
IZ crossbred with Bos taurus & Poorer & 349 & $\mathrm{IZ} \times \mathrm{BT}++$ \\
IZ crossbred with B. taurus & Better & 688 & $\mathrm{IZ} \times \mathrm{BT}+++$ \\
IZ crossbred with a higher proportion of & Better & 1,230 & $\mathrm{BT}++++$ \\
B. taurus or pure-bred B. taurus & & & \\
\hline
\end{tabular}

${ }^{1}$ Feed cost is the annual cost of feed at the herd level, according to the scenario of "current production system."

${ }^{2}$ Using terminology from this paper, where IZ = indigenous zebu; IZ $\times$ GZ is IZ crossbred with Guzerat; IZ $\times$ BT is IZ crossbred with B. taurus; and BT is IZ crossbred with a higher proportion of B. taurus or pure-bred B. taurus. The number of + denotes annual feed cost, with + low and ++++ high. 
Table 3. Number of households and animals for the dairy enterprise types ${ }^{1}$

\begin{tabular}{|c|c|c|c|c|c|c|c|}
\hline Item $^{2}$ & \multicolumn{7}{|c|}{ Dairy enterprise type ${ }^{3}$} \\
\hline Households [no. (\%)] & $62(30.7)$ & $44(21.8)$ & $23(11.4)$ & $16(7.9)$ & $14(6.9)$ & $33(16.3)$ & $10(5.0)$ \\
\hline Mature females [no. (\%)] & $537(40.0)$ & $237(17.7)$ & $171(12.7)$ & $96(7.2)$ & $71(5.3)$ & $187(13.9)$ & $44(3.3)$ \\
\hline
\end{tabular}

${ }^{1}$ At the time of census. Note that at any particular time during the survey period, the numbers of animals would vary from that given here due to entries and exits of animals from household herds throughout the survey period.

${ }^{2}$ Households and total animals presented in this table do not sum to the reported 220 households and 3,202 animals identified for the project. Households defined to an "other" majority breed type or to the minority BT +++ category have been removed from analysis.

${ }^{3}$ Dairy enterprise types are defined as a combination of breed type kept and level of management the animals are raised under, using annual cost of feed as a proxy. For breed type: IZ = indigenous zebu; IZ $\times$ GZ is IZ crossbred with Guzerat; IZ $\times$ BT is IZ crossbred with Bos taurus; and BT is IZ crossbred with a higher proportion of B. taurus or pure-bred B. taurus. The number of + denotes annual feed cost, with + low and ++++ high.

having 20 or fewer animals. Considering mature females only, the range was from 1 to 45 , with the majority $(83 \%)$ of households having 10 or fewer. Within the combined herd (i.e., over all households), the main animal types present were mature females (49\% of all animals), followed by young females (15\%), female calves, young males, and male calves $(11,10$, and $9 \%$, respectively), and mature males (7\%). The most represented breed group was IZ (49\% of all animals), followed by $\mathrm{IZ} \times \mathrm{BT}(22 \%)$ and $\mathrm{IZ} \times \mathrm{GZ}(21 \%)$; the least represented breed group was BT (9\%).

The number of households and animals for each of the different dairy enterprise types are given in Table 3. Here, households keeping more than one breed group of animals were classified by the main breed group they kept. For households, the most represented was IZ+ $(31 \%)$ and the least represented BT $++++(5 \%)$. This is reflective of exotic dairy cattle being relatively newly introduced to Senegal and only used by a small proportion of dairy cattle keepers (likely lower than the proportions indicated here, due to the purposeful sampling used in this study). The most represented animal breed type was IZ, with a total of 1,579 animals; the least was BT with only 169 animals.

\section{Economic Model}

The model used to determine net benefit and costbenefit ratio of the different household dairy enterprises is given in Marshall (2018). Briefly, this model provides a financial appraisal of smallholder dairy cattle enterprises. Benefits are generated from milk sale or household consumption (the latter valued at milk sale price) and animal sales. Costs are incurred due to animal healthcare, feed, water, and housing; labor, with household labor valued as per hired labor; those associated with reproduction, such as AI or purchase of a breeding animal; and those incurred in the sale of animals, such as brokerage or transport. Benefits and costs are calculated on a "per cow per annum" (pcpa) basis, where a cow is considered a breeding female attached to followers (i.e., her progeny). A herd model is used, where all animals are born into the herd (except for AI sires and purchased breeding bulls), and the fate of animals born into the herd is death or sale or being retained in the herd for use as a breeder with later sale as a cull for age cow or bull (see Figure 1). Age classes of animals used in the model were calf, young, and mature (see definitions above), with the maximum age of mature male and female animals being allowed to differ. Labor, water, and animal housing costs were considered herd-level invariant given the relatively small herd sizes under consideration: in the model, these costs were attributed equally to each breeding cow. Net benefit ${ }_{\text {pcpa }}$ was calculated as the difference between the benefit ${ }_{\text {pcpa }}$ and cost $_{\text {pcpa }}$, whereas the cost-benefit ratio was calculated as 1:(benefit ${ }_{\text {pcpa }} /$ cost $\left._{\text {pcpa }}\right)$.

\section{Model Scenarios}

Model scenarios, unless otherwise stated, were parameterized as follows. They assumed a herd size of 8 adult (breeding) cows, reflecting a typical herd size of the study herds. Animal and economic level parameters were as given in Table 4 (see also below and in the Appendix). The reproductive scenarios used were bull born in own herd for IZ and IZ $\times$ GZ dairy enterprise types, and $\mathrm{AI}$ for $\mathrm{IZ} \times \mathrm{BT}$ and $\mathrm{BT}$ dairy enterprise types, reflecting the most common reproductive practices used by the different dairy enterprise types.

Note that the model estimated net benefit and costbenefit ratio for each of the different dairy enterprise types; however, a variance around these estimates was not obtained. This was because many of the input parameters were single estimates for each dairy enterprise type (e.g., milk yield because it was calculated as a 
best-fit lactation curve across all animals within a breed type and management level, or because the parameter was estimated as a mode). Thus, formal statistical comparison between the net benefit and cost-benefit ratio between the different scenarios was not performed.

\section{Estimation of Parameters}

The parameters presented in Table 4, 35 in total, were estimated from survey data. Parameters estimated at the animal level (e.g., mortality rates, milk yields, animal sale price, feeding costs) were calculated for each animal group (combinations of breed, management level, sex, and age) using individual animal data.
Parameters estimated at the household level (e.g., the cost of labor, animal housing) were calculated for each dairy enterprise type from household data. Further details for individual parameters are given in the Appendix.

Any data collected while animals were transhumant (i.e., moving with herders away from the home base in search of pasture and water, which occurred during part of the survey period for 35 of the 220 households), was not used, as the quality of these data could not be verified. Thus, the estimated parameters apply to non-transhumant herds.

It was not possible to determine the accuracy of parameter estimates in all cases because of the ap-

\section{Breeding male Artificial insemination (purchased bull)}

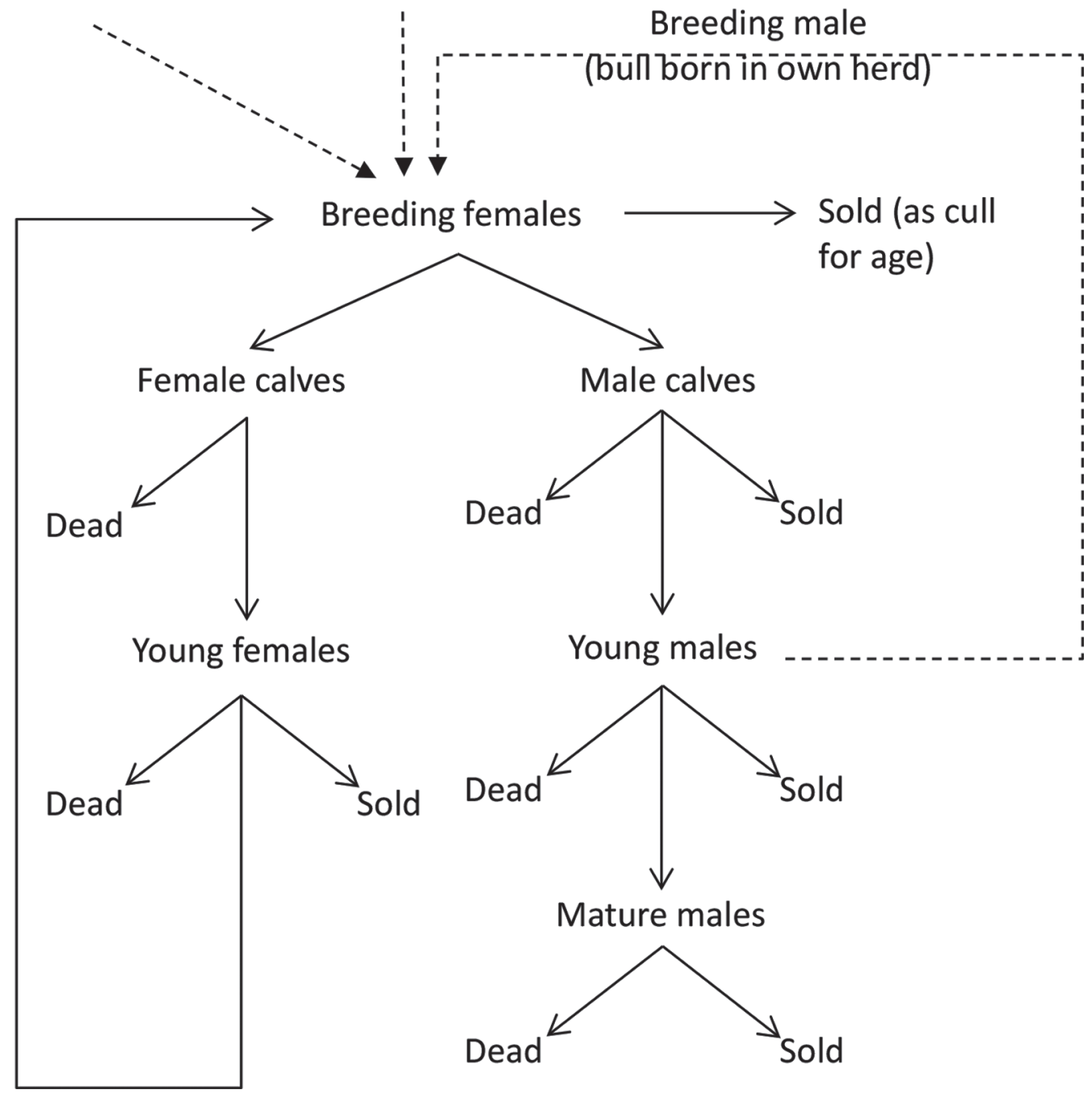

Figure 1. Illustration of the herd model utilized (adapted from Marshall, 2018). The 3 alternate reproductive scenarios on the male side are shown (dotted lines). Calf, young, or mature animals are sold, or die, uniformly over the time they are in that category, except in relation to female sale, which occurs at the end of the young period. 
Table 4. Parameters used in the model, as estimated from animal and household data, for the dairy enterprise types ${ }^{1}$

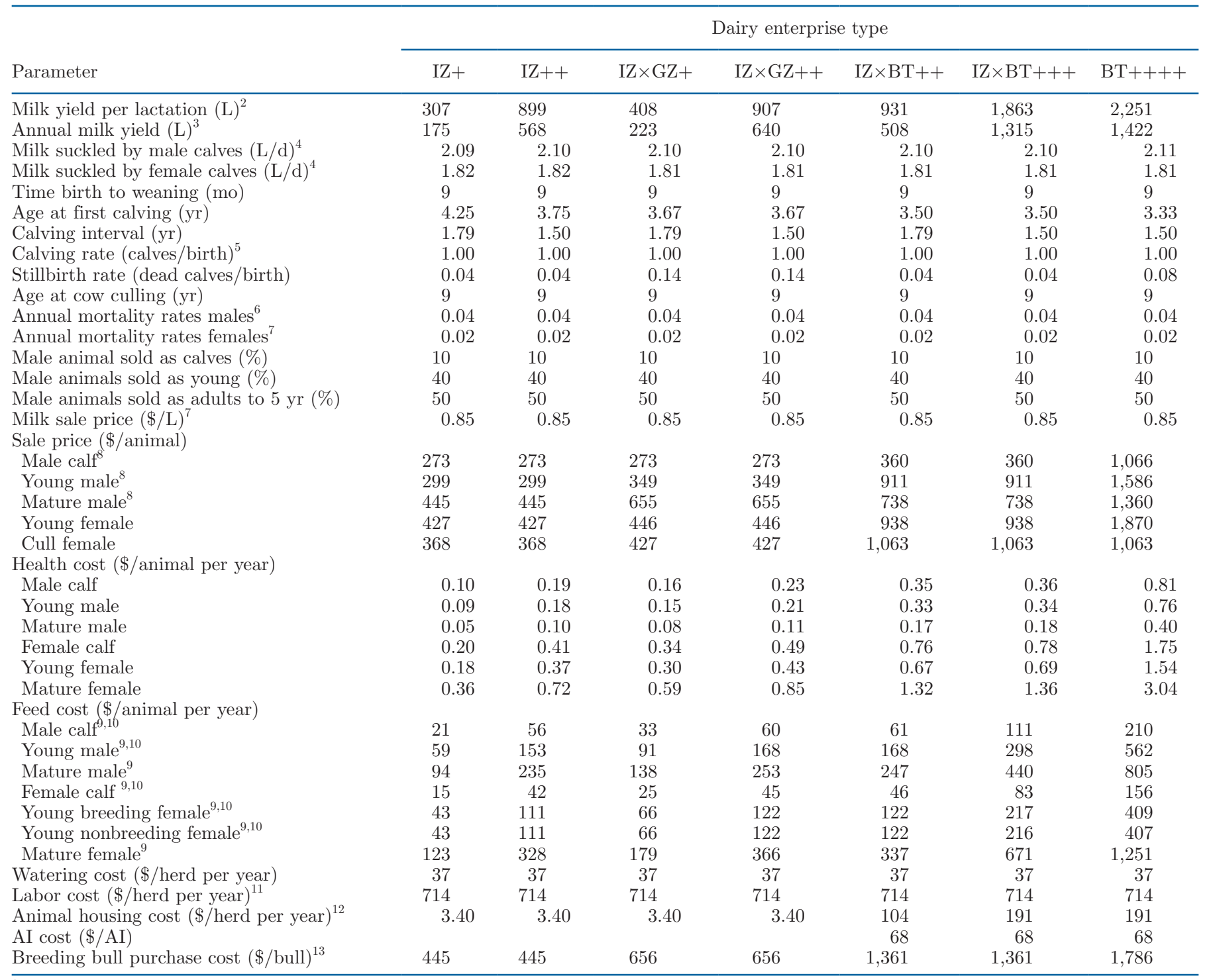

${ }^{1}$ Dairy enterprise types are defined as a combination of breed type kept and level of management the animals are raised under, using annual cost of feed as a proxy. For breed type: IZ = indigenous zebu; IZ $\times$ GZ is IZ crossbred with Guzerat; IZ $\times$ BT is IZ crossbred with Bos taurus; and BT is IZ crossbred with a higher proportion of B. taurus or pure-bred B. taurus. The number of + denotes annual feed cost, with + low and ++++ high.

${ }^{2}$ Averaged over 3 lactations, from lactation yields calculated separately for first and later parities, not including milk suckled by the calves.

${ }^{3}$ Averaged across dry and lactating cows, not including milk suckled by the calves.

${ }^{4}$ Averaged over the suckling period.

${ }^{5}$ Includes those born both dead or alive.

${ }^{6}$ Mortality rates did not differ for calf, young or mature cohorts.

${ }^{7}$ Applied to both milk sold and milk consumed by the household.

${ }^{8}$ The proportion of males sold as calf, young, and mature, of the total sold, was $0.10,0.40$, and 0.50 , respectively.

${ }^{9}$ Assumes no cost associated with pasture grazing.

${ }^{10}$ Calculated daily when animals are growing (i.e., until they reach mature age) and shown here as an average across the calf or young period.

${ }^{11}$ Household labor was valued at the same cost as hired labor.

${ }^{12}$ Considers building and maintenance costs, and the proportion of the building used for dairy animals, assuming 15-yr building life span.

${ }^{13}$ Breeding bulls were used for 2 yr before being sold. 
proach by which some parameters were estimated (see Appendix). However, it should be borne in mind that this accuracy will vary according to parameter type and the number of animals or households on which the parameter is being estimated. In particular, care should be taken in interpreting results for $\mathrm{BT}++++$ enterprises, as relatively few animals and households were categorized into this group.

Although economic data were collected in the local currency of Senegal (the West African CFA franc), economic parameters are reported here in United States dollars using a conversion ratio of $\$ 1=588.24$ CFA.

\section{Parameter Overview}

An overview of some of the key parameters, and how they vary between the different dairy enterprise types, follows. Milk yield per lactation (excluding that suckled by the calves) notably varied between the different dairy enterprise types, ranging from $307 \mathrm{~L}$ for IZ+ to $2,251 \mathrm{~L}$ for $\mathrm{BT}++++$ (a 7.3-fold difference). These milk yields are similar to that found for other studies in Africa (Das et al., 1999; Tadesse and Dessie, 2003; Millogo et al., 2008; Fayeye et al., 2013; Galukande et al., 2013). Age at first calving was between 3.3 and $4.3 \mathrm{yr}$, whereas calving intervals were 1.5 to $1.8 \mathrm{yr}$, again aligning with that previously reported for Africa (Marshall et al., 2011, 2013; Ejlertsen et al., 2012a,b; Galukande et al., 2013). Mortality rates were reasonably low across all dairy enterprise types and age classes of animals (0.02 to 0.04 ).

The sale price of milk was the same for all dairy enterprise types (there was no milk quality-based payment scheme operating in the study sites) at $\$ 0.85 / \mathrm{L}$. The sale price of male animals as young or mature (when they were most commonly sold) was highest for BT animals (by a considerable margin), followed by $\mathrm{IZ} \times \mathrm{BT}, \mathrm{IZ} \times \mathrm{GZ}$, and finally IZ (which had the lowest sale price). The sale price of young female and cull for age cows followed a similar pattern. Surprisingly, no difference in sale price was observed for animals of the same breed type raised under different management levels. For males, the highest and lowest sale prices were for $\mathrm{BT}++++$ young males at $\$ 1,586$ per animal and IZ+ calves at $\$ 273$ per animal, respectively. For females, these were $\mathrm{BT}++++$ young females at $\$ 1,700$ per animal and IZ+ cull for age cows at $\$ 368$ per animal, respectively. The very high sale price of BT animals compared with other breed types likely reflects their current rarity and may change in the future.

Purchased feed was a major expense, for example, at between $\$ 123$ to $\$ 1,251$ per year for mature females (cows). Purchased feed costs were (by definition) highest for ++++ , followed by,+++++ , and finally + . For the mature females, the feed costs for,+++++++ , and ++ were, on average, 8.3-, 4.2-, and 2.3-fold higher than that of + . Note that purchased feeds could be a supplement to pasture grazing. No cost was assigned to pasture grazing, as this was commonly on communal grazing lands that the farmers could access for free. Labor costs were estimated at $\$ 714$ per herd per year for all dairy enterprise types. Housing costs, which were substantive only for the $\mathrm{IZ} \times \mathrm{BT}$ and $\mathrm{BT}$ dairy enterprise types, where walled structures were built, were $\$ 104$ and $\$ 191$ per herd per year, respectively. The cost of healthcare was limited for all dairy enterprise types (generally less than $\$ 2$ per animal per year). This is likely reflective of health conditions commonly going unnoticed, untreated, and unreported (Tebug et al., 2015; Salmon, 2017), challenges in accessing veterinarian services (Salmon, 2017), or both.

\section{RESULTS AND DISCUSSION}

\section{Current Production Systems}

We found a 7.4-fold difference in net benefit between the most and least beneficial dairy enterprise type, meaning significant livelihood gains could be made by many smallholder dairy keepers by optimizing both dairy breed type and management system (Figure 2 and Table 5). The most net-beneficial and cost-beneficial dairy enterprise type was $\mathrm{IZ} \times \mathrm{BT}+++$, with a net benefit of $\$ 758$ pcpa and cost-benefit ratio of 1:1.66. This dairy enterprise type, based on improved dairy cattle genetics and management, is still not commonly adopted in Senegal, despite various initiatives to this end (Seck et al., 2016). The least net beneficial and cost-beneficial dairy enterprise type was IZ + , where net benefit was $\$ 102$ pcpa and the cost-benefit ratio 1:1.22. This is the traditional, and likely most commonly practiced, cattle-keeping system in Senegal (Seck et al., 2016). Interestingly, the keeping of pure, or near pure, exotic dairy animals under good management $(\mathrm{BT}++++)$ did not result in the highest net benefit, despite these animals having the highest milk yields. This was due to the high costs, particularly for feed, associated with keeping these animals (e.g., in comparing $\mathrm{BT}++++$ with $\mathrm{IZ} \times \mathrm{BT}+++$, the former had 1.1-foldhigher benefits but 1.5-fold-higher costs).

Benefit in this system was due to milk and animal sale (in some smallholder dairy systems, the sale of manure is important; however, this was not the case for these study sites). Milk accounted for most of the 
Table 5. Net benefit (\$/cow per year) for the dairy enterprise types ${ }^{1}$ under different scenarios ${ }^{2}$

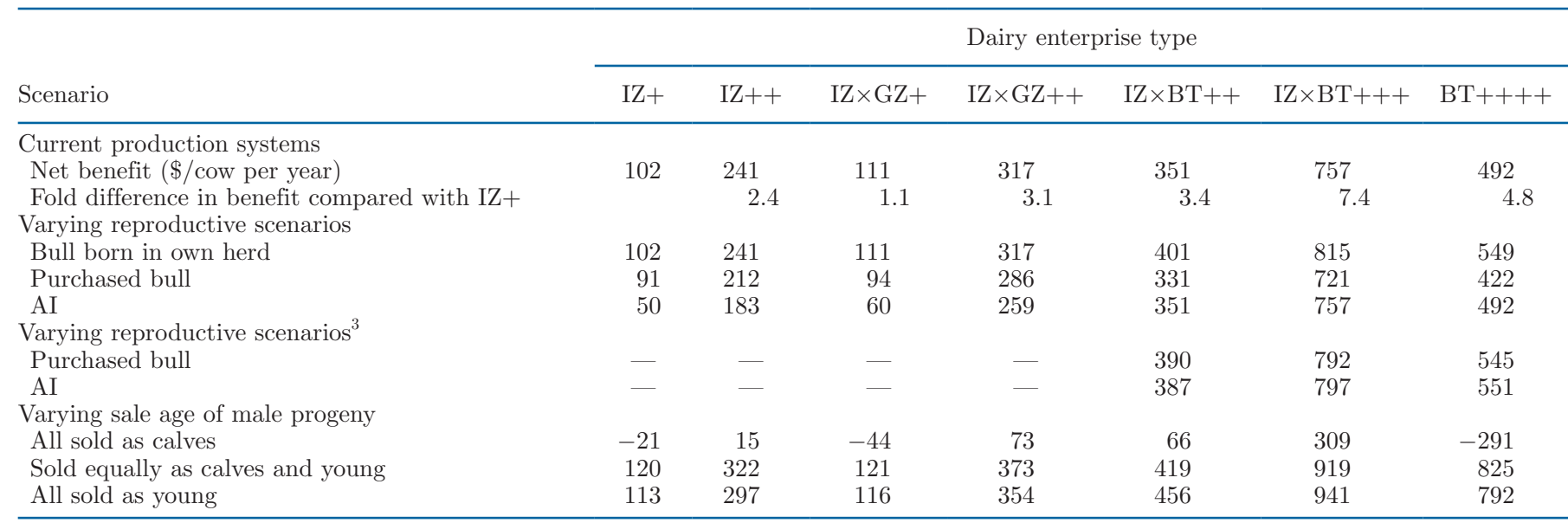

${ }^{1}$ Dairy enterprise types are defined as a combination of breed type kept and level of management the animals are raised under, using annual cost of feed as a proxy. For breed type: IZ = indigenous zebu; IZ $\times$ GZ is IZ crossbred with Guzerat; IZ $\times$ BT is IZ crossbred with Bos taurus; and BT is IZ crossbred with a higher proportion of B. taurus or pure-bred B. taurus. The number of + denotes annual feed cost, with + low and ++++ high.

${ }^{2}$ All values are net benefit (\$/cow per year) under different enterprise types apart from the fold difference in benefit of current enterprise types to the IZ+ type.

${ }^{3}$ With herd size increased to 12 cows for $\mathrm{IZ} \times \mathrm{BT}$ and 16 cows for $\mathrm{BT}$.

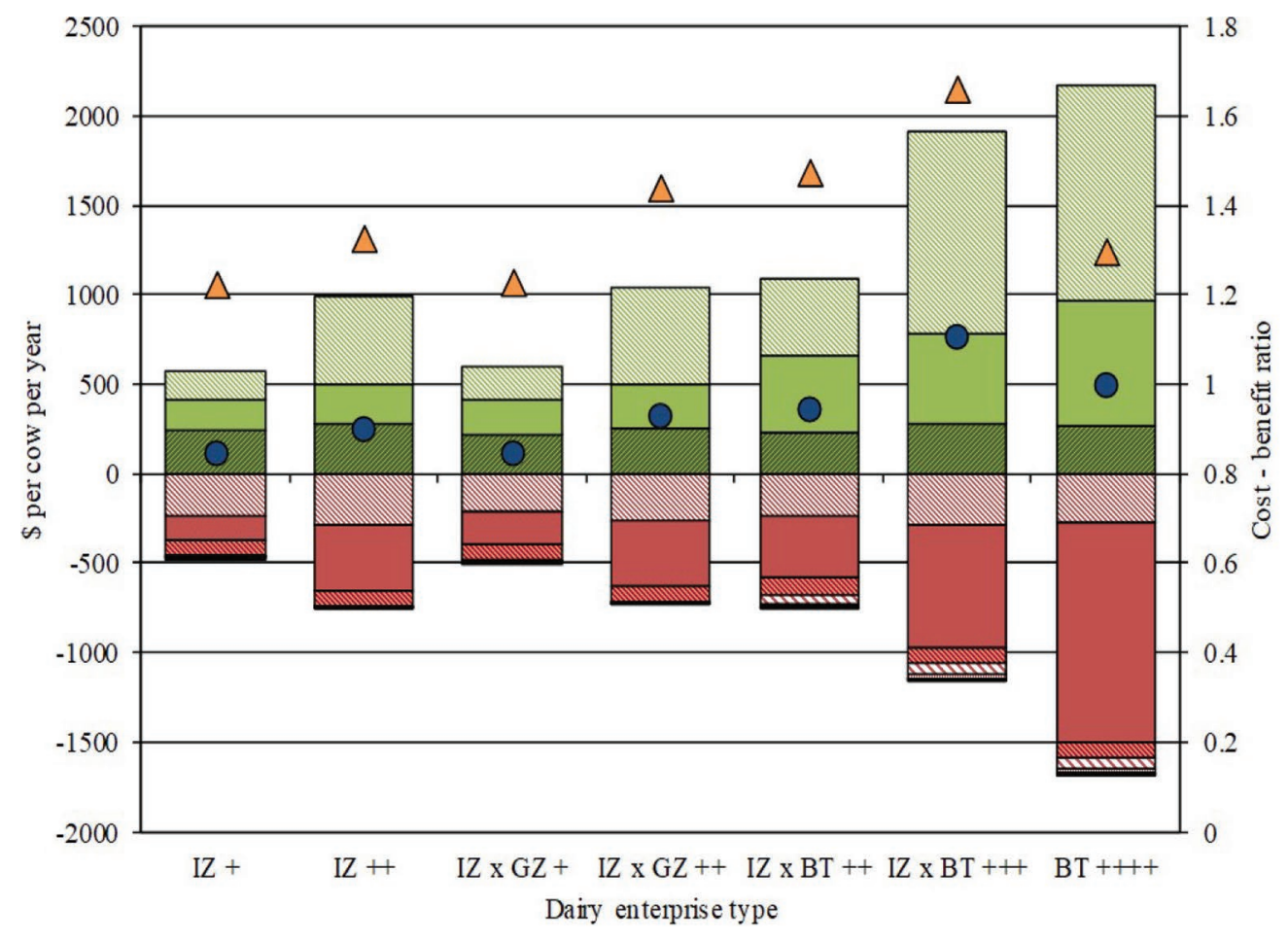

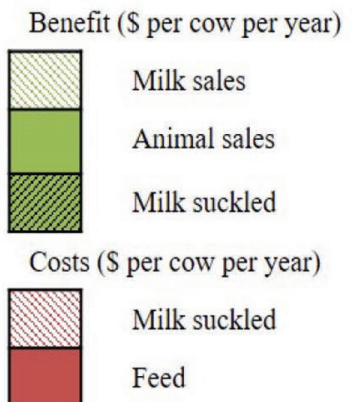

Feed

Labour

Reproduction

Housing

Watering

Health

Net benefit ( $\$$ per cow per year)

Cost-benefit ratio

Figure 2. Benefit components, cost components (shown as the negative of the actual cost), and net benefit (\$ per cow per year; left axis); and the benefit component of the cost-benefit ratios (right axis) for the dairy enterprise types. Dairy enterprise types are defined as a combination of breed type kept and level of management the animals are raised under, using annual cost of feed as a proxy. For breed type: IZ = indigenous zebu; IZ $\times$ GZ is IZ crossbred with Guzerat; IZ $\times$ BT is IZ crossbred with Bos taurus; and BT is IZ crossbred with a higher proportion of B. taurus or pure-bred B. taurus. The number of + denotes annual feed cost, with + low and ++++ high. 
benefit (61 to $78 \%$, depending on the enterprise type), inclusive of milk sold or consumed in the households, as well as that suckled by the calf (which typically occurred until calves were about 9 mo of age). Herd types with lower milk yield (where milk yield refers to that actually milked, rather than calf suckled) had a greater proportion of their milk value allocated to calf suckling compared with herds with higher milk yield. For example, almost two-thirds of the milk value for IZ+ herds went to maintaining calves, whereas for $\mathrm{IZ} \times \mathrm{BT}+++$, it was one-fifth of the milk value. If considering only milk and animal sales (i.e., those generating cash revenue for the household), milk sale accounted for 45 to $69 \%$ of the total benefit. In breaking down the benefit from animal sales, the proportions were 2 to $3 \%$ (depending on the enterprise type) for calves, 14 to $20 \%$ for young males, 20 to $34 \%$ for mature males, 9 to $22 \%$ for young female, and 32 to $45 \%$ for mature females. For males, this reflects the observed practice of male animals being sold up to $5 \mathrm{yr}$ of age, with few (10\%) sold as calves. For females, this reflects that most females born into the herd are retained for use as breeders and later sold as a cull for age cows.

The greatest cost to the household dairy enterprise was the provision of nutrition to the animals (either milk for calves or actual feed), which accounted for 79 to $89 \%$ of total costs (depending on the enterprise type). Within each breed group, households with a higher level of management had a 2- to 3-times-higher purchased feed cost compared with households with lower levels of management, the latter being more likely to rely on free grazed pastures to maintain their animals (Salmon, 2017). Likewise, herds with exotic BT genetics had a greater feed cost than herds with IZ or IZ $\times$ GZ genetics, due to higher use of more costly supplementary feeds in the BT herds (Salmon, 2017). For example, the annual feed cost for $\mathrm{IZ} \times \mathrm{BT}+++$ was about 2 -fold higher than that for $\mathrm{IZ} \times \mathrm{BT}++$ and 5 -fold higher than that for IZ+. The next major costs were labor (which accounted for 5 to $19 \%$ of the total costs), female reproductive costs for herds using AI; that is, IZ $\times \mathrm{BT}$ or $\mathrm{BT}$ (3 to $7 \%$ of the total costs), and animal housing for herds where shaded structures were built, again $\mathrm{IZ} \times \mathrm{BT}$ or $\mathrm{BT}(1.5$ to $2.0 \%$ of the total cost). Other minor costs were for watering ( 0.3 to $1 \%$ of the total costs), healthcare (0.1 to $0.3 \%$ of the total costs), and animal housing for IZ and $\mathrm{IZ} \times \mathrm{GZ}(0.1$ to $0.3 \%$ of total costs; this may be, for example, to buy rope for fencing).

Notably, the model suggested that all breed types provided a higher net benefit when a higher level of management input was used (Figure 2). For IZ, this was 2.4-fold higher, for IZ $\times$ GZ 2.9-fold higher, and for $\mathrm{IZ} \times \mathrm{BT} 2.2$-fold higher. This indicates that it is cost effective for livestock keepers to invest in higher levels of input management to improve the production and net benefit of their herds. A comparison of the animallevel parameters for these different dairy enterprise types, where milk yields, for example, increased 2- to 3 -fold with improved management alone, reinforces the recognition that livestock in sub-Saharan Africa do not regularly meet their genetic potential for production due to the harsh environmental conditions under which they must perform, including from low-input management practices (Chagunda et al., 2004; Ayenew et al., 2009; Garg et al., 2013).

In this study, we cannot partition the value of improved genetics from the effects of better management input, as management levels were not consistent across breed groups (a result of the study using field data). However, 3 scenarios had roughly similar feed costs (and thus presumably feed levels), which can be thus be used to make some comparisons to this end. These were $\mathrm{IZ}++, \mathrm{IZ} \times \mathrm{GZ}++$, and $\mathrm{IZ} \times \mathrm{BT}++$, where feed costs were $\$ 365, \$ 371$, and $\$ 349$ pcpa, respectively (Table 2 ). Here, lactation milk yields differed only slightly, at 899, 907, and $931 \mathrm{~L}$, respectively, suggesting that genetics is not a large contributing factor to milk yields at this level of management. Unfortunately, there were no study households keeping IZ or IZ $\times$ GZ genetics under +++ or higher management, where a differentiation in milk yields could be expected (given that GZ and, in particular, BT breeds, have been heavily selected for this trait). Such a study (perhaps additionally considering not managing versus managing the environment for heat stress) is warranted.

\section{Changing Herd Size}

In considering a range of herd sizes ( 1 to 16 breeding females, plus their followers) an increased net benefit per cow was observed with increasing herd size, although with diminishing returns (Figure 3). This was due to the costs of labor, housing, and water, being considered constant irrespective of the herd size, as explained above. The model suggests that small herd sizes (with 3 or fewer breeding females) can have a negative net benefit. Minimum herd sizes that were (just) net beneficial ranged from 2 to 4 , depending on the dairy enterprise type. Whatever the herd size, $\mathrm{IZ} \times \mathrm{BT}$ herds with a higher level of management $(+++)$ gave the highest net benefit.

In extrapolating these results to larger herd sizes (beyond 16 breeding females), it should be borne in mind that a herd size will be reached where additional investments in labor, housing, and water would be required. This would result in a decrease in net benefits (due to 


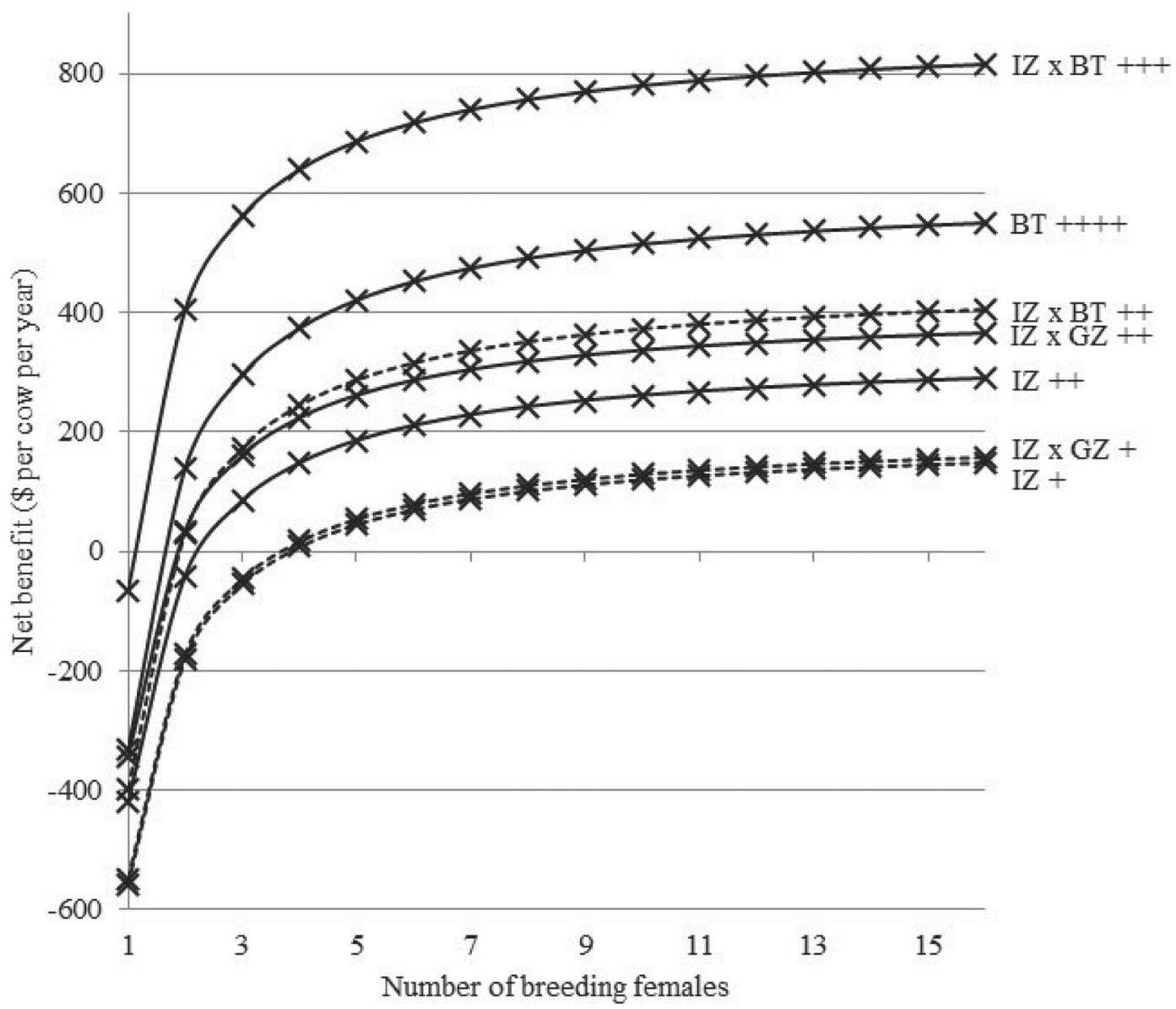

Figure 3. Net benefit (\$ per cow per year) with varying herd size, as the number of breeding females kept, for the dairy enterprise types. Dairy enterprise types are defined as a combination of breed type kept and level of management the animals are raised under, using annual cost of feed as a proxy. For breed type: IZ = indigenous zebu; IZ $\times \mathrm{GZ}$ is IZ crossbred with Guzerat; IZ $\times$ BT is IZ crossbred with Bos taurus; and BT is IZ crossbred with a higher proportion of B. taurus or pure-bred B. taurus. The number of + denotes annual feed cost, with + low and ++++ high.

the additional costs), following which net benefit would increase (with diminishing returns) as herd size further increases.

\section{Alternative Reproductive Scenarios}

Reproductive options available to farmers within the study sites included use of a bull that was born into their own herd, AI, or purchase of a breeding bull. For all dairy enterprise types, the most net beneficial of these was using a bull for free (Table 5 ; however, unless farmers were to swap bulls, this practice will lead to unacceptably high levels of inbreeding over time (the effects of which were not included in the model). For dairy enterprises keeping IZ and IZ $\times$ GZ animals, the next most net-beneficial reproductive strategy was bull purchase (with profit 0.85 to 0.90 of that of bull born into own herd, and assuming the bull was used for $2 \mathrm{yr}$ before sale); for $\mathrm{IZ} \times \mathrm{BT}$ and $\mathrm{BT}$ herds, the next most net-beneficial reproductive strategy was use of AI (with net benefit 0.87 to 0.93 of that of a bull born into own herd). The latter can be attributed to the high purchase price of breeding bulls with exotic genetics and the relatively small herd size of 8 breeding cows. Net benefit from purchased bulls or AI was about equal for the $\mathrm{IZ} \times \mathrm{BT}$ scenario with 12 cows and the BT scenario with 16 cows, and then was increasingly more favorable for purchased bulls as the herd size increased. This being the case, use of AI has numerous advantages, including typically larger sire selection choice (compared with buying breeding animals) and less risk of sexually transmitted reproductive disease, and thus may remain preferred.

\section{Male Calves Sold Earlier}

Male animals born into the herds were observed to be kept up to $5 \mathrm{yr}$ of age before sale. To test the net 
Table 6. Percentage change in net benefit (\$ per cow per year) when each economic parameter is increased in isolation by $10 \%$ for the dairy enterprise types ${ }^{1,2}$

\begin{tabular}{|c|c|c|c|c|c|c|c|}
\hline Economic parameter & \multicolumn{7}{|c|}{ Dairy enterprise type } \\
\hline Feed cost & -12.96 & -15.13 & -16.52 & -11.70 & -9.94 & -9.10 & -25.00 \\
\hline Animal sale price & 17.69 & 9.11 & 18.06 & 7.58 & 12.19 & 6.69 & 14.10 \\
\hline Labor costs & -8.72 & -3.70 & -8.03 & -2.81 & -2.54 & -1.18 & -1.81 \\
\hline AI costs & -3 & - & - & - & -1.43 & -0.76 & -1.17 \\
\hline Healthcare costs & -0.06 & -0.06 & -0.09 & -0.05 & -0.06 & -0.03 & -0.11 \\
\hline
\end{tabular}

${ }^{1}$ Dairy enterprise types are defined as a combination of breed type kept and level of management the animals are raised under, using annual cost of feed as a proxy. For breed type: IZ = indigenous zebu; IZ $\times$ GZ is IZ crossbred with Guzerat; IZ $\times$ BT is IZ crossbred with Bos taurus; and BT is IZ crossbred with a higher proportion of B. taurus or pure-bred B. taurus. The number of + denotes annual feed cost, with + low and ++++ high.

${ }^{2}$ Changes to net benefit of the same magnitude, but in the opposite direction, were observed when reducing economic parameters by $10 \%$.

${ }^{3}$ No values for $\mathrm{AI}$ for IZ and $\mathrm{IZ} \times \mathrm{GZ}$ enterprise types, as these did not use AI.

benefit of selling males at earlier ages (compared with the standard scenario where 10,40 , and $50 \%$ of male progeny were sold as calves, young, and mature animals to $5 \mathrm{yr}$, respectively), scenarios were run with male progeny either all sold as calves, equally sold as calf or young, or all sold as young (Table 5). For IZ, IZ $\times$ GZ, and BT dairy enterprise types, where the young male scale price was moderately increased over the calf sale price (by 10, 28, and $49 \%$, respectively), it was most net beneficial to sell males equally as calf and young, with net benefit increasing by 9 to $68 \%$. For the IZ $\times$ BT dairy enterprise types, where young male sale price was noticeably higher than the calf sale price (153\%), the most net beneficial option was to sell all males as young, with net benefit increasing by 24 to $30 \%$. Thus, dairy enterprises can increase net benefit by optimizing when they sell their male animals. In practice, however, this may be difficult for households to achieve, due to the selling of animals for a variety of reasons, including emergency sales (as was reported for nearly one-third of the study animals sold).

\section{Sensitivity Analysis of Net Benefits}

A sensitivity analysis was performed to determine the change in net benefit if economic parameters changed by $10 \%$ of their current value (Table 6 ). As expected, with benefits based on milk and animal sales value, both these parameters have a notable effect on net benefits. Likewise, as feed costs constitute a large proportion of total herd costs, changes to feed costs have a notable effect on net benefits, followed by labor costs.

Further analysis of the influence of milk price on net benefit indicated that if milk price were to increase above the current price, $\mathrm{IZ} \times \mathrm{BT}+++$ dairy enterprise types would still have the highest profit, even though the increase in profit would be highest for $\mathrm{BT}++++$ households as they produce the most milk (Figure 4). Should milk prices drop, BT ++++ would be the most likely to experience loss-making, at around a 40\% drop in milk prices from the baseline. Other herd types would become loss-making if milk prices were to drop by between 60 and $90 \%$.

The IZ $\times \mathrm{BT}+++$ dairy enterprise type remained with the highest net benefit with increased cost of purchased feed (Figure 5), suggesting that this dairy enterprise type is the most resilient to increases in feed price. The $\mathrm{BT}++++$ herd appeared to be the most vulnerable to feed price increases, with households becoming lossmaking with a $40 \%$ increase in feed cost: this stems from the higher proportion of total costs attributable to purchased feed (at $73 \%$, vs. 29 to $60 \%$ for the other scenarios). If feed costs were to decrease by more than half, the $\mathrm{BT}++++$ "exotic" herds would become the most net beneficial because their high milk benefits would no longer be outweighed by the high feed costs.

In considering changes to animal productivity parameters, net benefit was most sensitive to total milk produced (both that milked and suckled by the calves; Table 7), as expected, given that this is where the largest proportion of herd benefits is derived. The next most sensitive parameters were age at first calving and calving interval, which affect the number of lactations per lifetime of animal, and thus also milk production, as well as the number of animals born and thus sold. Regardless of which parameter was changed, $\mathrm{IZ} \times \mathrm{BT}+++$ gave the highest net benefit. These results highlight milk production and reproduction as being the target production parameters to improve among these herds. It also indicates that efforts should be taken to ensure 
that reported milk and reproductive parameters are accurate, as these have the greatest effect on model results.

\section{Synthesis of Results}

The keeping of IZ $\times$ BT breed type under good management $(+++)$ gave the highest net benefit and costbenefit ratio, by a considerable margin, under a range of scenarios. Although attribution could not be shown here, this result was most likely due to the improved genetics, a combination of the well-adapted local breeds with the highly productive exotic breeds, and ability for this to be expressed by good management. It is unfortunate that not all combinations of breed type and management level were included in the study: in particular, IZ $\times$ GZ cross-breed under good management $(+++)$ should not be ruled out as promising because it was not tested.

\section{Methodological Considerations}

A major strength of the methodology used in this study was its in situ nature, with data obtained from farms undertaking their normal practices. This reduces concerns about genotype by environment interactions, which are often raised in relation to research station trials where management practices can differ from that of the farmers. One limitation of in situ studies, however, is that options to be compared are limited to what farmers currently practice, and thus some potentially interesting options can be missed. In this study, this was the case for dairy enterprises keeping IZ and $\mathrm{IZ} \times \mathrm{GZ}$ animals under high management levels $(+++$ and ++++ ) and, of course, for any breed or crossbreed types not present that may be more beneficial.

A key factor in this study was the availability of genomic approaches to assign breed composition to individual animals. Previously, this would have been

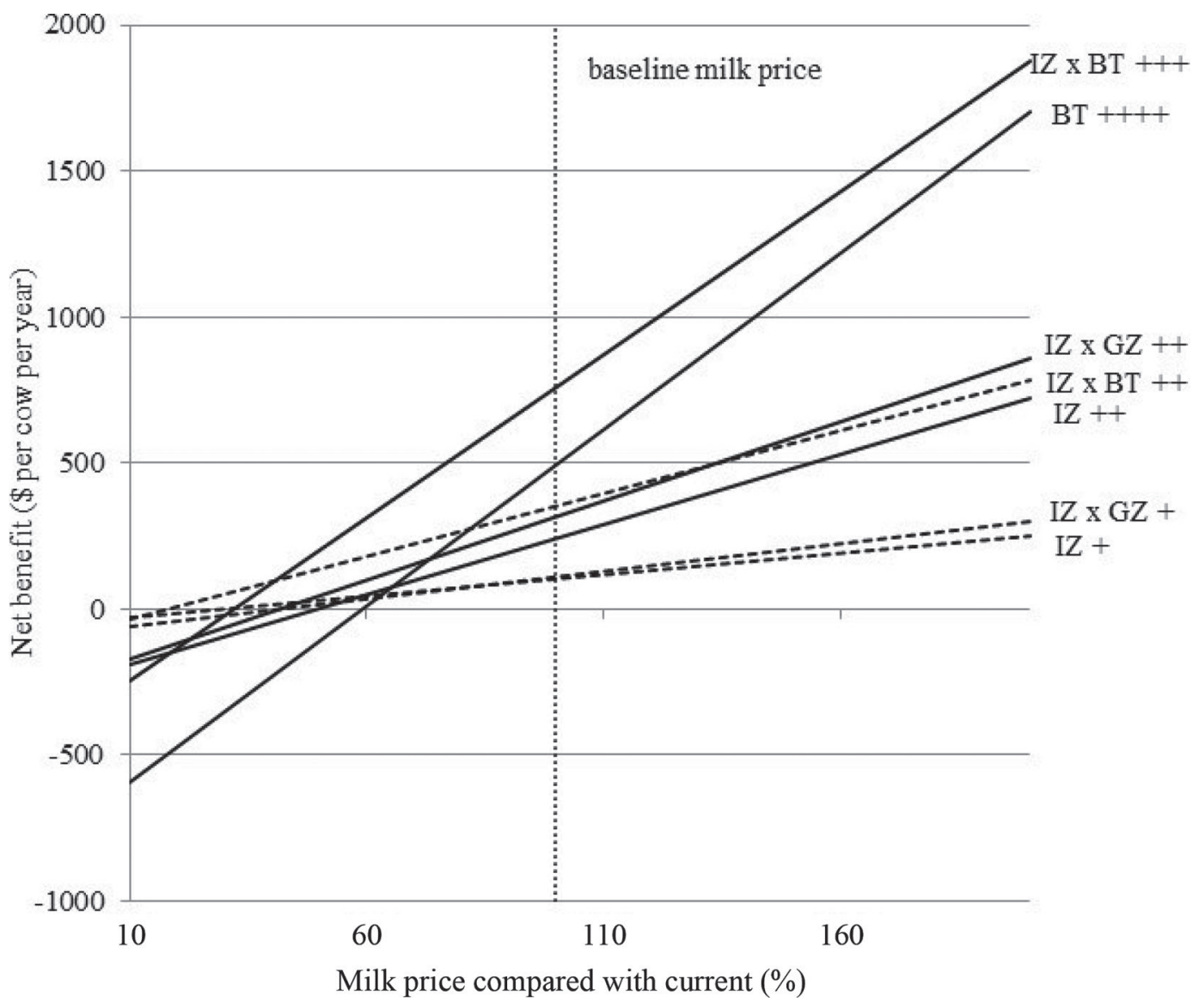

Figure 4. Change in net benefit (\$ per cow per year), when milk price is altered by varying proportions (\%) from the current milk cost (shown by the vertical dashed line) for the dairy enterprise types. Dairy enterprise types are defined as a combination of breed type kept and level of management the animals are raised under, using annual cost of feed as a proxy. For breed type: IZ $=$ indigenous zebu; IZ $\times$ GZ is IZ crossbred with Guzerat; IZ $\times$ BT is IZ crossbred with Bos taurus; and BT is IZ crossbred with a higher proportion of B. taurus or pure-bred B. taurus. The number of + denotes annual feed cost, with + low and ++++ high. 
Table 7. Percentage change in net benefit (\$/cow per year) when each animal parameter was made more favorable, ${ }^{1}$ in isolation, by $10 \%$ for the dairy enterprise types ${ }^{2}$

\begin{tabular}{|c|c|c|c|c|c|c|c|}
\hline Animal parameter & \multicolumn{7}{|c|}{ Dairy enterprise type } \\
\hline Total milk produced $^{3}$ & 14.5 & 20.0 & 17.0 & 17.1 & 12.3 & 14.8 & 24.6 \\
\hline Productive life & 2.9 & 1.8 & 2.0 & 1.2 & 0.6 & 0.6 & 4.6 \\
\hline Mortality rate & 0.5 & 1.2 & 0.9 & 0.9 & 0.3 & 0.6 & 0.8 \\
\hline Stillbirth rate & 0.5 & 0.0 & 1.5 & 0.2 & 0.3 & 0.0 & 0.2 \\
\hline Age at first calving & 7.2 & 5.1 & 6.1 & 3.8 & 2.8 & 2.4 & 8.4 \\
\hline
\end{tabular}

${ }^{1}$ More favorable refers to an increase in milk yield and productive life and a decrease in all other parameters. Changes to net benefit of the same magnitude, but in the opposite direction, were observed when animal parameters were made less favorable $10 \%$.

${ }^{2}$ Dairy enterprise types are defined as a combination of breed type kept and level of management the animals are raised under, using annual cost of feed as a proxy. For breed type: IZ = indigenous zebu; IZ $\times$ GZ is IZ crossbred with Guzerat; IZ $\times$ BT is IZ crossbred with Bos taurus; and BT is IZ crossbred with a higher proportion of B. taurus or pure-bred B. taurus. The number of + denotes annual feed cost, with + low and ++++ high.

${ }^{3}$ Inclusive of both that milked and milk suckled by the calves.

difficult, if not impossible, due to the lack of pedigree recording by the participating farmers and the indiscriminate nature of the cross-breeding practiced in the study studies. Here, we assigned animals to breed groups based on their estimated proportions of zebu and $B$. taurus. If the study had significantly more animals within the IZ $\times$ BT and BT breed groups, it would make sense to extend this to the exact breed or crossbreed types.

The economic model used in this study was developed to capture the specificities of the study system, such as the sale of male animals at relatively late ages compared with systems in developed countries. The model has some limitations, including not capturing all functions that cattle play in these systems, such as the provision of manure for crop fertilizer or the keeping of cattle for savings or insurance purposes (Marshall, 2014). Some opportunity costs were not considered in this model, particularly costs of feed from grazing lands, which were most commonly communal (public) grazing areas. Such costs are difficult to capture (because the area used and time spent vary over time); in addition, they are likely to be small because the alternative use of grazing lands is limited (poor soil conditions, common property making private investments difficult if not impossible). Additionally, variance in net benefit was not calculated (see explanation in the Methods section). This is important when considering risk, because risk-adverse livestock keepers may not wish to adopt a technology that, although beneficial on average, is expected to have adverse outcomes for some (Salmon et al., 2018a). Another consideration is that the model assumed that farmers already had an established herd of the breed group under consideration: the costs of moving from one breed type to another were not accounted for. Finally, it should be recognized that, due to the indiscriminate crossing within the study sites, each crossbred group $(\mathrm{IZ} \times \mathrm{GZ}, \mathrm{IZ} \times \mathrm{BT}, \mathrm{BT})$ would be a mix of $\mathrm{F}_{1}$ and $\mathrm{F}_{2}$ animals, backcrosses, and various other crossing types. This means that any effects of heterosis would be averaged over these (unknown) crossing types and that these effects may differ from that where the crosses represented, for example, only $\mathrm{F}_{1}$ animals.

Many economic and animal-level parameters were estimated as part of this study, which in itself is a valuable outcome, given the paucity of such data. That some parameters may not have been accurately estimated is recognized (see Materials and Methods section); however, these were used due to lack of alternatives, with sensitivity analysis performed.

\section{Other Studies}

No similar study could be found in Senegal or West Africa with which to compare these results. In East Africa, an Ethiopian study on smallholder dairy (Dayanandan, 2011) reported a 4.4-fold-higher net return (\$403 vs. $\$ 92 \mathrm{pcpa})$ and higher cost-benefit ratio (1:3 vs. 1:2.2) for the keeping of crossbred (local $\times$ exotic) cattle under better management compared with local cattle under traditional management. This was largely driven by the increased milk yield of crossbred cattle, which was 4 -fold higher than that of local cattle. Another study on Ethiopia smallholder dairy systems (Tekeba et al., 2012) found 4.0- to 4.8-fold-higher net returns for crossbreds compared with local breeds. Other similar studies have been performed in South Asia (Bangladesh, India, and Pakistan) and found crossbreed cattle to be more profitable or net beneficial by 2.9- to 9.7fold as well as more cost-beneficial by 1.1- to 1.8-fold (Sayeed et al., 1994; Ali et al., 2000; Islam et al., 2008, 2010; Mondal et al., 2010). Although these results still 


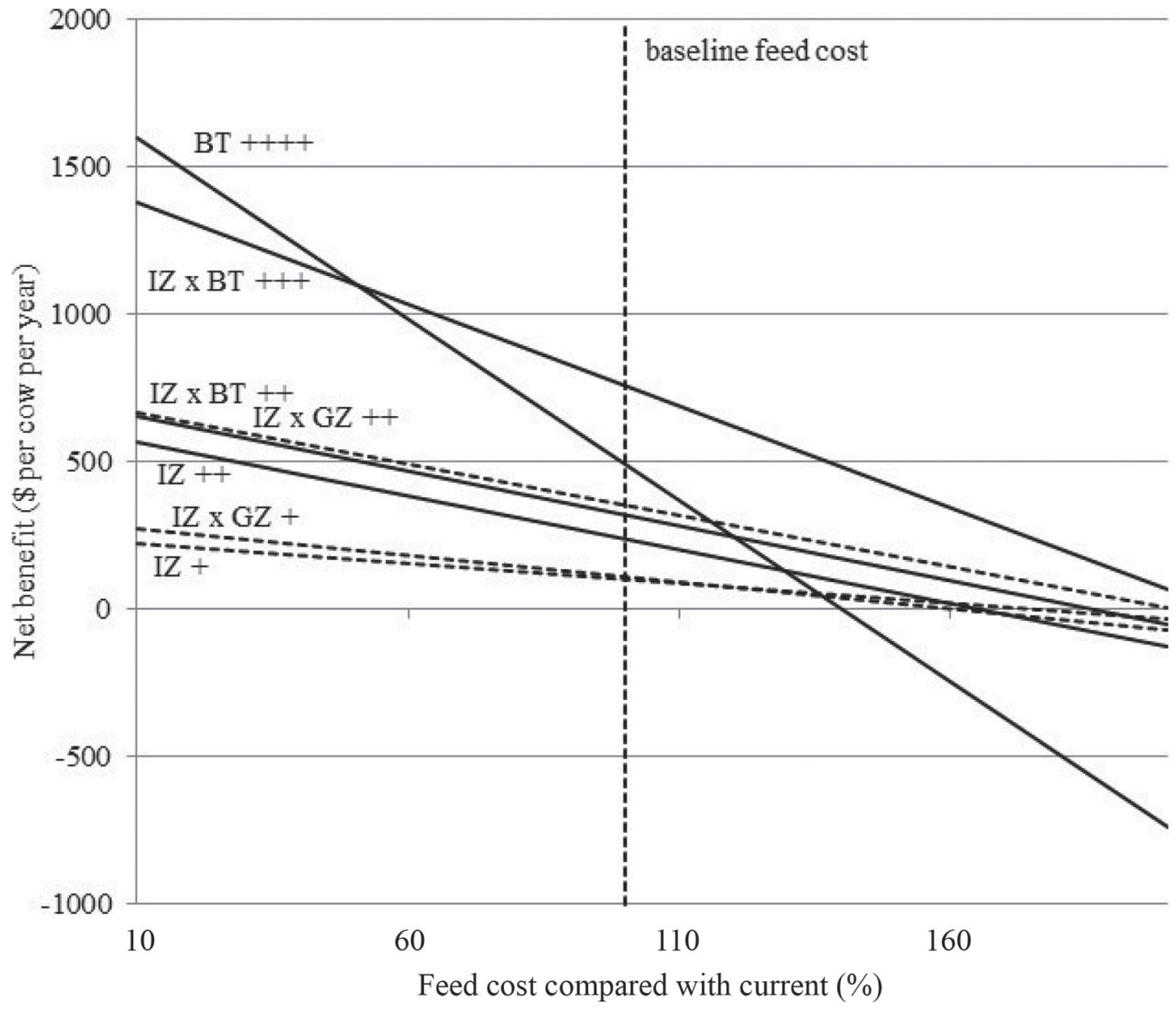

Figure 5. Change in net benefit (\$ per cow per year) when feed cost is altered by varying proportions (\%) from the current feed cost (shown by the vertical dashed line) for the dairy enterprise types. Dairy enterprise types are defined as a combination of breed type kept and level of management the animals are raised under, using annual cost of feed as a proxy. For breed type: IZ = indigenous zebu; IZ $\times$ GZ is IZ crossbred with Guzerat; IZ $\times$ BT is IZ crossbred with Bos taurus; and BT is IZ crossbred with a higher proportion of B. taurus or pure-bred B. taurus. The number of + denotes annual feed cost, with + low and ++++ high.

represent very few studies applied to a limited number of systems, that the crossbreeds were more profitable or beneficial in all cases suggests the promising nature of improved (productive and adapted) dairy cattle in smallholder production systems. That many other smallholder dairy cattle systems in LMICs are increasingly using crossbred animals also attests to this.

\section{Trade-Off Analysis and Recommendations to Strengthen the Senegal Dairy Sector}

The economic analysis presented here forms part of a broader trade-off analysis designed to assist stakeholders in Senegal dairy to make evidence-based decisions on which dairy cattle breeds and management systems to promote or adopt. Other aspects considered in the trade-off analysis include milk yield (which links to food and nutritional security), the breed preferences of female and male livestock keepers, environmental sustainability focusing on greenhouse gas emissions intensity, food safety focusing on aflatoxins, and intrahousehold dynamics in terms of labor provision, payment of costs, and control of benefits (Marshall et al., 2016a,b, 2017; Walugembe et al., 2016; Salmon, 2017; Salmon et al., 2018a,b). Although we recognize that this does not capture all potential trade-offs, it is a significant extension to simply considering yields or net benefit alone. We also recognize that the applicability of these recommendations to other locations (beyond the study sites) depends on how closely they share economic, geographic, and other factors.

While the cross of indigenous zebu and B. taurus was the most net beneficial and cost beneficial, had close to the highest milk yields, and was the preferred breed type of both female and male cattle keepers (this paper and Marshall et al., 2016b), there were some interesting trade-offs. The first was that milk from the crossbred cattle was likely contaminated with aflatoxin, due to cow 
consumption of aflatoxin-contaminated supplementary feeds (Marshall et al., 2016a), resulting in milk potentially unsafe for human consumption. Human consumption of aflatoxins can lead to hepatocellular carcinoma and may be an underlying determinant of stunted child growth (Gong et al., 2016). The second was that the keeping of crossbred cattle was associated with a higher level of market orientation of the household dairy enterprise (more milk produced and sold), and that fewer women controlled the income from the sale of milk in higher compared with lower market-orientation households (Walugembe et al., 2016). This result aligns with other studies that show a shift in the control of benefits from women to men because household enterprises that benefit women become increasingly commercially oriented. This is a concern because, for example, rural women tend to invest more in child nutrition than men do (Njuki et al., 2011a,b; Galiè, 2019).

Several key recommendations to dairy stakeholders in Senegal can be suggested based on this trade-off analysis, including establishing a national dairy cattle breeding scheme to ensure the availability of high genetic quality cross-breed dairy cows and bulls; assisting farmers to access and optimally manage these animals by facilitating access to services including, where required, on credit; removing the key constraint to dairy posed by insufficient, poor quality, or unsafe dairy cattle feed; and building the capacity of female and male livestock keepers to both optimally manage genetically improved animals and ensure equitable benefit (Marshall et al., 2016b, 2017).

\section{CONCLUSIONS}

In this study, we demonstrated that the combined intervention of improved dairy cattle genetics and management and increased milk production and cow reproductive performance can improve the livelihoods of the rural poor in Senegal as well as livestock production self-sufficiency for Senegal. The evidence base generated in this study is being shared with stakeholders in Senegal dairy, including policy makers, extension workers, livestock keepers, and development organizations, for more informed decision-making. Given the paucity of studies of this nature in LMIC and their usefulness to stakeholders, similar studies in other LMIC livestock systems, particularly those where livestock keepers are interested in intensifying, are strongly recommended.

\section{ACKNOWLEDGMENTS}

The authors extend special thanks to the women and men livestock keepers who participated in this project, as well as the field team who worked with these farmers to collect the data. We thank additional researchers, in particular Lotta Lassila (University of Helsinki, Helsinki, Finland), for their contributions to the wider project. We also gratefully acknowledge the project funders, which were the Finnish Ministry of Foreign Affairs, under the FoodAfrica program, and the CGIAR Research Program on Livestock and Fish (ILRI, Nairobi, Kenya). The authors have not stated any conflicts of interest.

\section{REFERENCES}

Alexandratos, N., and J. Bruinsma. 2012. World agriculture towards 2030/2050: the 2012 revision. ESA Working paper No. 12-03. Food and Agriculture Organization of the United Nations (FAO), Rome, Italy.

Ali, M. H., A. G. Miah, M. L. Ali, U. Salma, M. A. S. Khan, and M. N. Islam. 2000. A comparative study on the performance of crossbred and indigenous (Zebu) cows under the small holder dairy farming Condition in Gaibandha district. Pak. J. Biol. Sci. 3:1080-1082. https://doi.org/10.3923/pjbs.2000.1080.1082.

Andrieu, N., K. Descheemaeker, T. Sanou, and E. Chia. 2015. Effects of technical interventions on flexibility of farming systems in Burkina Faso: Lessons for the design of innovations in West Africa. Agric. Syst. 136:125-137. https://doi.org/10.1016/j.agsy .2015.02.010.

Ayenew, Y. A., M. Wurzinger, A. Tegegne, and W. Zollitsch. 2009. Performance and limitation of two dairy production systems in the North western Ethiopian highlands. Trop. Anim. Health Prod. 41:1143-1150. https://doi.org/10.1007/s11250-008-9294-3.

Baldi, A. and D. Gottardo. 2017. Livestock production to feed the Planet. Animal protein: A forecast of global demand over the next years. Beyond Anthropocentrism 5:65-71.

Beal, T., C. Belden, R. Hijmans, A. Mandel, M. Norton, and J. Riggio. 2015. Country profiles: Senegal. Sustainable Intensification Innovation Lab. Accessed June 21, 2018. http://gfc.ucdavis.edu/ profiles/rst/sen.html.

Broutin, C., and O. Diokhané. 2000. La Filière "Lait et produits laitiers" au Sénégal. Réseau Technologie et Partenariat en Agroalimentaire; Relais National du Sénégal. Dakar, Senegal.

Chagunda, M. G. G., E. W. Bruns, J. M. King, and C. B. A. Wollny. 2004. Evaluation of the breeding strategy for milk yield of Holstein Friesian cows on large-scale dairy farms in Malawi. J. Agric. Sci. 142:595-601. https://doi.org/10.1017/S0021859604004666.

Climate-Data.org. 2019. Climate: Senegal. Accessed June 13, 2019. https://en.climate-data.org/africa/senegal-187/.

Corander, J., P. Marttinen, J. Sirén, and J. Tang. 2008. Enhanced Bayesian modelling in BAPS software for learning genetic structures of populations. BMC Bioinformatics 9:539. https://doi.org/ 10.1186/1471-2105-9-539.

Das, S. M., H. Wiktorsson, and M. Forsberg. 1999. Effects of calf management and level of feed supplementation on milk yield and calf growth of Zebu and crossbreed cattle in the semi-arid tropics. Livest. Prod. Sci. 59:67-75. https://doi.org/10.1016/S0301 $-6226(98) 00206-1$.

Dayanandan, R. 2011. Production and marketing efficiency of dairy farms in highland of Ethiopia-An economic analysis. Int. J. Enterp. Comput. Bus. Syst. 1:1-34.

Delgado, C., M. W. Rosegrant, H. Steinfeld, S. Ehui, and C. Courbois. 2001. Livestock to 2020: the next food revolution. Outlook Agric. 30:27-29. https://doi.org/10.5367/000000001101293427.

Diouf, M. N., K. Marshall, and M. L. Fadiga. 2016. Analysis of the dairy germplasm value chain in Senegal. ILRI Project Report. International Livestock Research Institute (ILRI), Nairobi, Kenya. 
Ejlertsen, M., J. Poole, and K. Marshall. 2012a. Sustainable management of globally significant endemic ruminant livestock in West Africa: Estimate of livestock demographic parameters in Senegal. ILRI Research Report 29. International Livestock Research Institute (ILRI), Nairobi, Kenya.

Ejlertsen, M., J. Poole, and K. Marshall. 2012b. Sustainable management of globally significant endemic ruminant livestock in West Africa: Estimates of livestock demographic parameters in Mali. ILRI Research Report 31. International Livestock Research Institute (ILRI), Nairobi, Kenya.

Ema, P. N., L. Lassila, A. Missohou, K. Marshall, M. Tapio, S. F. Tebug, and J. Juga. 2018. Milk production traits among indigenous and crossbred dairy cattle in Senegal. Afr. J. Food Agric. Nutr. Dev. 18:13572-13587. https://doi.org/10.18697/ajfand.83 .17155

Ezanno, P., A. Ickowicz, and R. Lancelot. 2005. Relationships between N'Dama cow body condition score and production performance under an extensive range management system in Southern Senegal: Calf weight gain, milk production, probability of pregnancy, and juvenile mortality. Livest. Prod. Sci. 92:291-306. https://doi .org/10.1016/j.livprodsci.2004.09.001.

FAO. 2012. Livestock sector development for poverty reduction: An economic and policy perspective. Livestock's many virtues. Food and Agriculture Organization of the United Nations, Rome, Italy.

Fayeye, T. R., A. H. A. Badmos, and H. O. Okin. 2013. Milk yield and quality of Holstein and Jersey breeds of cattle in Kwara State, Nigeria. J. Agric. Res. Dev. 12:11-18.

Feedipedia. 2019. Feedipedia: Animal feed resources information system. INRA; CIRAD, FAO; Association Française de Zootechnie. Accessed June 14, 2019. https://www.feedipedia.org/.

Galiè, A. 2019. Leveraging gender for food and nutrition security through agriculture. Pages 426-431 in Vol. 3. Encyclopedia of Food Security and Sustainability. Elsevier, Amsterdam, the Netherlands.

Galukande, E., H. Mulindwa, M. Wurzinger, R. Roschinsky, A. O. Mwai, and J. Sölkner. 2013. Cross-breeding cattle for milk production in the tropics: Achievements, challenges and opportunities. Anim. Genet. Resour. 52:111-125. https://doi.org/10.1017/ S2078633612000471.

Garg, M. R., P. L. Sherasia, B. M. Bhanderi, B. T. Phondba, S. K. Shelke, and H. P. S. Makkar. 2013. Effects of feeding nutritionally balanced rations on animal productivity, feed conversion efficiency, feed nitrogen use efficiency, rumen microbial protein supply, parasitic load, immunity and enteric methane emissions of milking animals under field conditions. Anim. Feed Sci. Technol. 179:24-35. https://doi.org/10.1016/j.anifeedsci.2012.11.005.

Gong, Y. Y., S. Watson, and M. N. Routledge. 2016. Aflatoxin exposure and associated human health effects, a review of epidemiological studies. Food Saf. (Tokyo) 4:14-27. https://doi.org/10.14252/ foodsafetyfscj.2015026.

Herrero, M., P. K. Thornton, P. Gerber, and R. S. Reid. 2009. Livestock, livelihoods and the environment: understanding the tradeoffs. Curr. Opin. Environ. Sustain. 1:111-120. https://doi.org/10 .1016/j.cosust.2009.10.003.

ICAR. 2017. Procedure 2 of section 2 of ICAR guidelines - Computing of accumulated lactation yield. ICAR. Accessed June 14, 2019. https://www.icar.org/Guidelines/02-Procedure-2-Computing -Lactation-Yield.pdf.

ILRI. 2019. Options for the livestock sector in developing and emerging economies to 2030 and beyond. Pages 1-28 in Meat: The Future Series. World Economic Forum, Geneva, Switzerland.

IPCC. 2006. Chapter 10: Emissions from livestock and manure management. Intergovernmental Panel on Climate Change (IPSS). Accessed June 14, 2019. https://www.ipccnggip.iges.or.jp/public/ 2006gl/pdf/4_Volume4/V4_10_Ch10_Livestock.pdf.

Islam, M. M., A. H. Topader, and A. Rob. 2010. Comparative study on the cost benefit between indigenous and cross bred cows reared in rural area of Dinajpur district. Bangladesh J. Anim. Sci. 39:191196. https://doi.org/10.3329/bjas.v39i1-2.9696.
Islam, S., A. Goswami, and D. Mazumdar. 2008. Comparative profitability of cross breed and indigenous cattle in West Bengal. Indian Res. J. Ext. Educ. 8:28-30.

Jarrige, R. 1989. Ruminant nutrition: Recommended allowances and feed tables. INRA, Paris, France.

Lesnoff, M., S. Messad, and X. Juanes. 2010. 12MO: A cross-sectional retrospective method for estimating livestock demographic parameters in tropical smallholder farming systems. Agricultural Research Centre for International Development (CIRAD), Paris, France.

Liu, Z., R. Reents, F. Reinhardt, and K. Kuwan. 2000. Approaches to estimating daily yield from single milk testing schemes and use of am-pm records in test-day model genetic evaluation in dairy cattle. J. Dairy Sci. 83:2672-2682. https://doi.org/10.3168/jds.S0022 $-0302(00) 75161-7$

Marshall, K. 2014. Optimizing the use of breed types in developing country livestock production systems: a neglected research area. J. Anim. Breed. Genet. 131:329-340. https://doi.org/10.1111/jbg .12080

Marshall, K. 2018. Description of cost:benefit model developed for lowinput dairy systems typical of developing countries. ILRI Manual 29. International Livestock Research Institute (ILRI), Nairobi, Kenya.

Marshall, K., M. Ejlertsen, and J. Poole. 2011. Sustainable management of globally significant endemic ruminant livestock in West Africa: Estimate of livestock demographic parameters in the Gambia. ILRI Research Report 28. International Livestock Research Institute (ILRI), Nairobi, Kenya.

Marshall, K., M. Ejlertsen, and J. Poole. 2013. Sustainable management of globally significant endemic ruminant livestock in West Africa: Estimate of livestock demographic parameters in Guinea. ILRI Research Report 30. International Livestock Research Institute (ILRI), Nairobi, Kenya.

Marshall, K., A. Missohou, S. Tebug, I. Kagera, D. Grace, and J. Lindahl. 2016a. Aflatoxins in dairy cattle feed in Senegal. Page 522 in Tropentag 2016 Conference on Solidarity in a Competing World, Vienna, Austria. https://surumer.uni-hohenheim.de/fileadmin/ einrichtungen/surumer/Tropentag_2016-Book_of_abstracts.pdf.

Marshall, K., S. Tebug, J. Juga, M. Tapio, and A. Missohou. 2016b. Better dairy cattle breeds and better management can improve the livelihoods of the rural poor in Senegal. ILRI Research Brief 65 . International Livestock Research Institute (ILRI), Nairobi, Kenya

Marshall, K., S. Tebug, G. R. Salmon, M. Tapio, J. Juga, and A. Missohou. 2017. Improving dairy cattle productivity in Senegal. ILRI Policy Brief 22. International Livestock Research Institute (ILRI), Nairobi, Kenya.

Millogo, V., G. A. Ouedraogo, S. Agenauml, and K. SvennerstenSjaunja. 2008. Survey on dairy cattle milk production and milk quality problems in peri-urban areas in Burkina Faso. Afr. J. Agric. Res. 3:215-224.

Mondal, R. K., S. Sen, and S. J. Rayhan. 2010. A comparative economic analysis of local breed and cross breed milk cow in a selected area of Bangladesh. J. Sci. Found. 8:23-29. https://doi.org/ 10.3329 /jsf.v8i1-2.14616.

Njuki, J., S. Kaaria, A. Chamunorwa, and W. Chiuri. 2011a. Linking smallholder farmers to markets, gender and intra-household dynamics: Does the choice of commodity matter? Eur. J. Dev. Res. 23:426-443. https://doi.org/10.1057/ejdr.2011.8

Njuki, J., J. Poole, N. Johnson, I. Baltenweck, P. Pali, Z. Lokman, and S. Mburu. 2011b. Gender, livestock and livelihood indicators. International Livestock Research Institute (ILRI), Nairobi, Kenya.

Peixoto, M. G. C. D., C. F. Poggian, R. S. Verneque, A. A. Egito, M. R. S. Carvalho, V. M. Penna, J. A. G. Bergmann, L. F. Viccini, and M. A. Machado. 2010. Genetic basis and inbreeding in the Brazilian Guzerat (Bos indicus) subpopulation selected for milk production. Livest. Sci. 131:168-174. https://doi.org/10.1016/j .livsci.2010.03.015.

Salmon, G., N. Teufel, I. Baltenweck, M. van Wijk, L. Claessens, and K. Marshall. 2018a. Trade-offs in livestock development at farm 
level: Different actors with different objectives. Glob. Food Secur. 17:103-112. https://doi.org/10.1016/j.gfs.2018.04.002.

Salmon, G. R. 2017. Reducing the carbon footprint of Senegalese cattle systems through improved productivity. PhD Thesis. The University of Edinburgh, UK.

Salmon, G. R., K. Marshall, S. F. Tebug, A. Missohou, T. P. Robinson, and M. MacLeod. 2018b. The greenhouse gas abatement potential of productivity improving measures applied to cattle systems in a developing region. Animal 12:844-852. https://doi.org/ 10.1017/S1751731117002294.

Sayeed, M. A., S. M. A. Rahman, J. Alam, and J. Begum. 1994. Economics of milk production in Dhaka district-A case for Savar Thana. Asian-Australas. J. Anim. Sci. 7:49-55. https://doi.org/10 .5713 /ajas.1994.49

Seck, M., K. Marshall, and M. L. Fadiga. 2016. Policy framework for dairy development in Senegal. ILRI Project Report. International Livestock Research Institute (ILRI), Nairobi, Kenya.

Tadesse, M., and T. Dessie. 2003. Milk production performance of Zebu, Holstein Friesian and their crosses in Ethiopia. Livest. Res. Rural Dev. 15:1-9.

Tebug, S. F., A. R. Kamga-Waladjo, P. J. Ema, C. Muyeneza, O. Kane, A. Seck, M. T. Ly, and M. Lo. 2015. Cattle farmer awareness and behavior regarding prevention of zoonotic disease transmission in Senegal. J. Agromedicine 20:217-224. https://doi.org/ 10.1080/1059924X.2015.1010068.

Tebug, S. F., A. Missohou, S. S. Sabi, J. Juga, E. J. Poole, M. Tapio, and K. Marshall. 2018. Using body measurements to estimate live weight of dairy cattle in low-input systems in Senegal. J. Appl. Anim. Res. 46:87-93. https://doi.org/10.1080/09712119.2016 .1262265 .

Tekeba, E., M. Wurzinger, and W. Zollitsch. 2012. Effects of ureamolasses multi-nutrient blocks as a dietary supplement for dairy cows in two milk production systems in north-western Ethiopia. Livest. Res. Rural Dev. 24:1-4.

Walugembe, M., S. F. Tebug, M. Tapio, A. Missohou, J. Juga, K. Marshall, and M. F. Rothschild. 2016. Gendered intra-household contributions to low-input dairy in Senegal. Anim. Indust. Rep. 662: ASL R3078.

\section{ORCIDS}

K. Marshall ๑ https://orcid.org/0000-0003-4197-1455

G. R. Salmon (1) https://orcid.org/0000-0001-7932-5358

J. Juga (1) https://orcid.org/0000-0002-7207-1057

M. MacLeod ๑ https://orcid.org/0000-0003-2444-6886

J. Poole (๖) https://orcid.org/0000-0002-8570-794X

\section{APPENDIX}

Additional details on how the parameters used in the model were estimated from the survey data are given below.

\section{Milk Yield Per Lactation}

Milk yields per lactation, excluding milk suckled by the calves, were calculated separately for first and later parities, using only data from cows whose breed group had been confirmed by genomic information, and that had a known last calving date, age, and parity number. For the $\mathrm{IZ}+, \mathrm{IZ}++, \mathrm{IZ} \times \mathrm{GZ}+, \mathrm{IZ} \times \mathrm{GZ}++, \mathrm{IZ} \times \mathrm{BT}++$, $\mathrm{IZ} \times \mathrm{BT}+++$, and $\mathrm{BT}++++$ dairy enterprise types, the number of animals included in the analysis for first parity was $20,20,13,9,6,20$, and 7 , respectively, while that for later parities was $53,38,17,21,12,37$, and 9 , respectively. Cumulative yield over $365 \mathrm{~d}$ (approximately the average lactation length) were calculated using the test interval method as given in ICAR (2017). Test-day milk yields were calculated by summing milk yields from morning and evening milking: if one of these was missing it was predicted using a modified method of Liu et al. (2000), as explained in ICAR (2017). Some additional analysis on milk (including milk quality, although at breed-group level only) is given in Ema et al. (2018).

\section{Annual Milk Yield}

Annual milk yield was calculated as milk yield per lactation/calving interval in years. Here, milk yield per lactation was calculated as the average yield over the first and 2 later lactations, given the data indicated an average of 3 lactations per cow lifetime.

\section{Suckled Milk}

Milk suckled by calves per day until weaning was estimated separately for male and female calves. Milk suckling volume quantities were taken from Ezanno et al. (2005). The difference in milk suckled by sex, was estimated based on the different energy requirements (for growth and maintenance) of the different sex BW, according to the methodology applied in Salmon (2017).

\section{Age}

Age of animals at the time of an event (e.g., weaning, calving, sale) was determined based on the time period between that event and the animal's birthdate. Birthdates were recorded (to the day) for animals born during the survey period. For animals already in the herd at the start of the survey period or that entered the herd other than by birth (such as purchase), a best estimate of age was agreed between the farmer and enumerator (in years for animals $>12$ mo old; in months for animals $<12$ mo old) from which a birth year (and month for younger animals) was derived.

\section{Birth to Weaning Interval}

The time intervals from birth to weaning were calculated as the mode of the number of months from an animal being born to when it was weaned, from longitudinal survey data (where, across all groups, there were 276 records). As these modes were close for each of the groups and the range within each group was large, this parameter was set to the same value for each group (average of the group modes). 


\section{Age at First Calving}

Ages at first calving were calculated as average age of cows when their first calf was born from longitudinal survey data (where, across all groups, 166 first calving events were recorded).

\section{Calving Interval}

Calving interval was difficult to estimate because few animals calved twice during the longitudinal monitoring period (due to the long length of the calving interval). Given this, 2 approaches to estimating calving period were utilized. The first approach used 12-mo recall data (which was collected at the time of census) as described in Lesnoff et al. (2010). Here, a parturition rate was calculated based on number of calving events (which, across all groups, was 594) and time at risk (which, across all groups, was 968 years), and this rate inverted to give calving interval. This approach assumed calving events were equally distributed across the year, which is probably a fair assumption (given that seasonality of mating is rarely intentionally practiced). The second approach used a calving date from the longitudinal survey and a previous calving date as recalled by the farmer (n $=156$, across all dairy enterprise types, with additional calving intervals discarded due to being shorter than biologically possible, a result of farmer recall error), or 2 calving dates from the longitudinal survey $(\mathrm{n}=18)$. These 2 methods generally gave similar results and so were averaged. As noted, the estimated calving intervals were similar for $\mathrm{IZ}+, \mathrm{IZ} \times \mathrm{GZ}+$ and $\mathrm{IZ} \times \mathrm{BT}++$, an average of these was used in the model, and likewise for the remaining dairy enterprise types.

\section{Calving Rate}

Calving rates were calculated as number offspring born per parturition (birthing event) from longitudinal survey data (where, across all groups, 493 calving events were recorded).

\section{Stillbirth Rate}

Stillbirth rates were calculated as the total number of calves born dead over the total number of calves born (whether dead or alive) from longitudinal survey data (where, across all groups, 29 stillbirths were recorded over 493 calving events).

\section{Age of Cow Culling}

Ages of cow culling were determined by examining the distribution of age of females at the time of census (where, across all groups, 2,061 females had age records). It was defined as the earliest age where less than $10 \%$ of females remained.

\section{Mortality Rate}

Annual mortality rates were calculated as the annual hazard rate of natural death (i.e., excluding slaughtering) as annual mortality rate $=$ (number of natural deaths/total herd days $) \times 365$, from longitudinal survey data (where, across all groups, females had 81 natural deaths and 1,234,881 total herd days, and males had 60 natural deaths and 564,741 total herd days). Here, total herd days refers to the sum of days that individual animals were present over the longitudinal monitoring period. As values were similar (and low) for young, female, and mature animals within a sex (male or female), the average over young, female, and mature was used.

\section{Milk Sale}

Milk sale prices were calculated as the mode of milk sale price from longitudinal survey data (where, across all groups, 1,195 milk sale prices were recorded). Note the associated transport costs had a mode of zero; thus, milk sale prices were not adjusted for this.

\section{Animal Sale}

Animal sale prices were calculated as the average sale price of animals from longitudinal survey data (where, across all groups, 130 female and 182 males were sold with sale prices recorded). Note the associated transport and brokerage costs had a mode of zero; thus, animal sale prices were not adjusted for this.

\section{Proportion of Male Animals Sold at Different Age Classes}

The proportion of male animals sold for the different age classes were set as 10\% for calves, $40 \%$ for young and $50 \%$ for mature (sold up to 5 yr), based on examining the distributing of age of sale of males using recall (over the last year and taken at the time of census) and longitudinal monitoring data (where, across both surveys and for all groups, there were 298 animals sold with age records). These values were rounded from calculated values of $8.3,39.4$, and $52.3 \%$ for calves, young, and mature, respectively. The decision to set maximum sale age at 5 yr was determined by examining the distribution of age of males at the time of census (where, across all groups, 443 females had age records). It was 
defined as the earliest age at which less than $10 \%$ of males remained.

\section{Health}

Annual health costs were calculated as the total health costs divided by total herd days (see definition above) $\times 365$, from longitudinal survey data (where, across all groups, females had 199 health events recorded for a total cost of $\$ 1,963$ and $1,239,989$ total herd days and males had 54 health events recorded for a total cost of $\$ 26$ and 633,457 total herd days).

\section{Feed}

Annual feed costs were calculated based on the most common diets (feed baskets) for each of the dairy enterprise types, considering diet variation in wet (JulyOctober) and dry (November-June) seasons, from the longitudinal survey data (Table 8). The energy content of each feed basket was calculated using Feedipedia (2019) and Jarrige (1989). The daily DMI was then calculated based on the daily energy requirements of animals of different sexes, breed types, and management levels (using energy requirement calculations from IPCC, 2006). Between calving and weaning (at 9 mo), suckled milk was assumed to decrease linearly, with the energy requirement for growth, maintenance, and activity made up with calves starting to consume DM feed rations. Once animals were at mature weight, energy requirements for maintenance, activity, lactation, and reproduction were calculated on a per day basis. The energy requirement for lactation is dependent on milk production quantity and quality (fat content of the milk was considered by Ema et al., 2018). All other energy requirements are dependent on $\mathrm{BW}$, which were determined from growth curves derived from project weight data (Tebug et al., 2018). The daily feed intake per animal to maintain calculated energy requirements was costed using feed prices calculated from project (longitudinal survey) data, accounting for the seasonal (wet and dry) variation in these prices. Grazed feed, commonly pasture on communal grazing lands, was not costed, as access to this was free to the farmers. Further detail regarding the derivation of feed rations is given by Salmon (2017).

\section{Water}

Annual water cost was calculated as the average annual water costs across households (from baseline and longitudinal survey data). This included the cost of water access fees and water purchases, and equipment to provide water (predominantly water pumps, for which a 10-yr life span was assumed).

\section{Labor}

Annual labor cost to dairy was calculated for the most common labor type across all households (from longitudinal survey data), given that no major difference in labor for the different household dairy enterprise types was observed. This was adult men providing labor for $11.4 \mathrm{~h} / \mathrm{d}$ and adult women for $1.9 \mathrm{~h} / \mathrm{d}$, inclusive of both household and hired labor (where adult was defined as more than 15 yr of age). For hired men, the mode

Table 8. Feed ration components (\%) for the dairy enterprise types ${ }^{1}$ in wet and dry seasons ${ }^{2}$

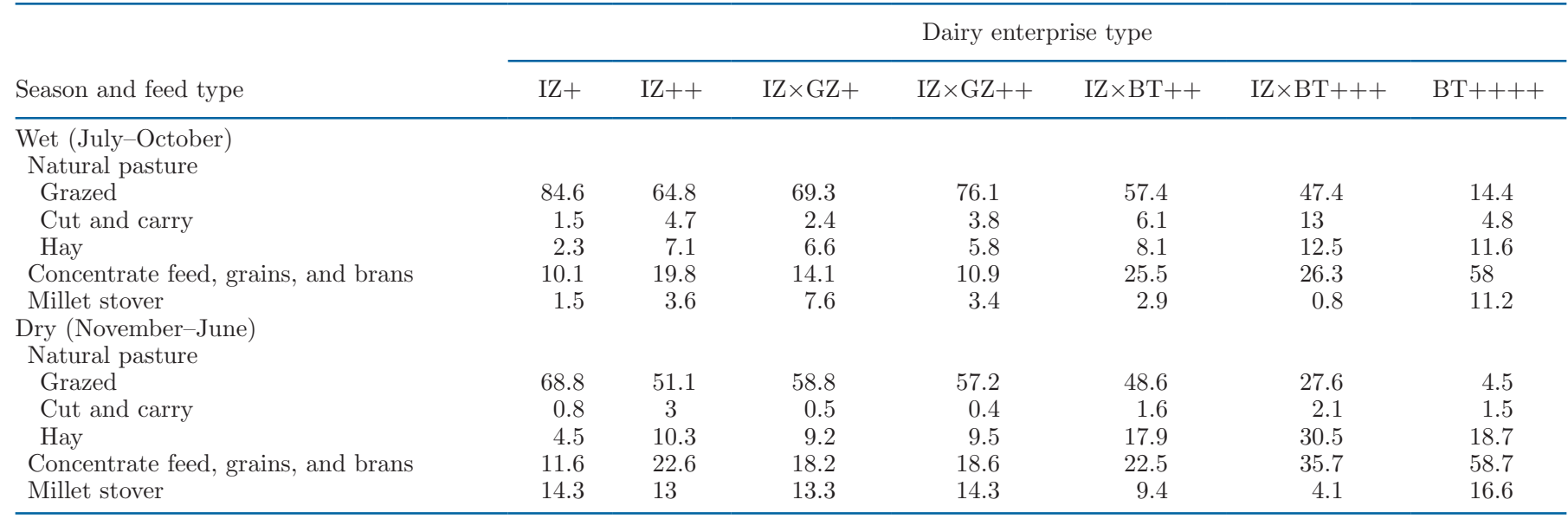

${ }^{1}$ Dairy enterprise types are defined as a combination of breed type kept and level of management the animals are raised under, using annual cost of feed as a proxy. For breed type: IZ = indigenous zebu; IZ $\times$ GZ is IZ crossbred with Guzerat; IZ $\times$ BT is IZ crossbred with Bos taurus; and BT is IZ crossbred with a higher proportion of B. taurus or pure-bred B. taurus. The number of + denotes annual feed cost, with + low and ++++ high.

${ }^{2}$ Adapted from Salmon (2017). 
of salary and benefits was used to cost both hired and household male labor. As few women were hired, the previous value for men was pro-rated, based on hours, to cost women's labor (whether hired or household).

\section{Animal Housing}

Annual animal housing cost was calculated for the main animal housing types used by the different groups of households. These were "no housing" (i.e., animals kept outside) for IZ and IZ $\times$ GZ animals, and "walled space partially covered by a roof" for $\mathrm{IZ} \times \mathrm{BT}$ and BT animals. For "no housing," the average of annual costs associated with keeping the animals outside (such as fencing or tethering costs) was used. For housing, the annual costs were calculated as the average (over households) of the construction cost for the animal house divided by 15 (for an assumed 15-yr life span), plus annual maintenance cost, and further considering the proportion of the structure used for dairy animals. As no trend between herd size and the animal housing cost was observed in the data, the animal housing costs used in the model were for a per-herd basis (thus, keeping a larger herd would result in a lower animal housing cost per animal).

\section{Al}

Artificial insemination costs were calculated as the mode of the AI costs, which included both the semen and AI service, from longitudinal survey data (where, across all groups, 291 AI costs had been recorded).

\section{Breeding Bull}

The breeding bull purchase price was calculated as the average purchase price of male animals of 3 and 4 yr of age from longitudinal survey data (where, across all groups, 23 males were purchased and had a purchase price). 